\title{
Modelling an unconventional closed-loop deep borehole heat exchanger (DBHE): sensitivity analysis on the Newberry volcanic setting
}

\author{
Hannah R. Doran ${ }^{* *} \mathbb{0}$, Theo Renaud ${ }^{2}$, Gioia Falcone ${ }^{1}$, Lehua Pan ${ }^{3}$ and Patrick G. Verdin ${ }^{2}$
}

\section{*Correspondence:}

h.doran.1@research.gla.ac.uk

1 James Watt School

of Engineering, University

of Glasgow, Glasgow G12

8QQ, UK

Full list of author information is available at the end of the article

\begin{abstract}
Alternative (unconventional) deep geothermal designs are needed to provide a secure and efficient geothermal energy supply. An in-depth sensitivity analysis was investigated considering a deep borehole closed-loop heat exchanger (DBHE) to overcome the current limitations of deep EGS. A T2Well/EOS1 model previously calibrated on an experimental DBHE in Hawaii was adapted to the current NWG 55-29 well at the Newberry volcano site in Central Oregon. A sensitivity analysis was carried out, including parameters such as the working fluid mass flow rate, the casing and cement thermal properties, and the wellbore radii dimensions. The results conclude the highest energy flow rate to be $1.5 \mathrm{MW}$, after an annulus radii increase and an imposed mass flow rate of $5 \mathrm{~kg} / \mathrm{s}$. At $3 \mathrm{~kg} / \mathrm{s}$, the DBHE yielded an energy flow rate a factor of 3.5 lower than the NWG 55-29 conventional design. Despite this loss, the sensitivity analysis allows an assessment of the key thermodynamics within the wellbore and provides a valuable insight into how heat is lost/gained throughout the system. This analysis was performed under the assumption of subcritical conditions, and could aid the development of unconventional designs within future EGS work like the Newberry Deep Drilling Project (NDDP). Requirements for further software development are briefly discussed, which would facilitate the modelling of unconventional geothermal wells in supercritical systems to support EGS projects that could extend to deeper depths.
\end{abstract}

Keywords: Closed-loop deep borehole heat exchanger, EGS, NDDP, T2Well, EOS1

\section{Introduction}

Geothermal energy is an ideal candidate to dominate the energy industry in the foreseeable low-carbon future. Holding a good reputation at providing a constant supply of heat and/or electricity, this mature baseload technology could aid the climate crisis by significantly reducing carbon emissions.

Conventional deep geothermal methods have been utilised to provide power production from natural hydrothermal reservoirs with these desired characteristics: a large heat source, highly permeable, sufficient supply of injected water, impermeable layer of cap rock, and a reliable recharge system (DiPippo 2015). Generally, these sites

c) The Author(s) 2021. This article is licensed under a Creative Commons Attribution 4.0 International License, which permits use, sharing adaptation, distribution and reproduction in any medium or format, as long as you give appropriate credit to the original author(s) and the source, provide a link to the Creative Commons licence, and indicate if changes were made. The images or other third party material in this article are included in the article's Creative Commons licence, unless indicated otherwise in a credit line to the material. If material is not included in the article's Creative Commons licence and your intended use is not permitted by statutory regulation or exceeds the permitted use, you will need to obtain permission directly from the copyright holder. To view a copy of this licence, visit http://creativeco mmons.org/licenses/by/4.0/ 
are unique and restricted by location, severely limiting the true potential of geothermal energy-according to the International Energy Agency, this resource could generate $1400 \mathrm{TWh}$ per year by 2050 while avoiding $800 \mathrm{Mt}$ of $\mathrm{CO}_{2}$ (IEA 2011). This largely untapped resource demands alternative solutions to compete in the renewable energy market, specifically exploiting unconventional methods to extract heat, notably from petrothermal sources where permeability and/or porosity are lacking (Falcone et al. 2018). There are significant research gaps for deep unconventional methods where the geothermal gradient is larger than the mean value of $25-30^{\circ} \mathrm{C} / \mathrm{km}$ (Olasolo et al. 2016). In an Enhanced Geothermal System (EGS), cold water is injected at high pressure into the subsurface to stimulate fractures, hence creating an artificial reservoir (Olasolo et al. 2016). The first EGS project was in Los Alamos (New Mexico), previously defined as a Hot Dry Rock (HDR) project due to lack of natural water saturation in basement rocks (Olasolo et al. 2016; Breede et al. 2013). EGSs are currently under technical review as they are associated with the risk of inducing seismic activity (Lu 2018). Examples of abandoned EGS projects due to induced seismicity are the Basel project in Switzerland ( $\mathrm{Lu} \mathrm{2018)}$ and the Pohang project in South Korea (Kim et al. 2018). Fundamental research and development on Supercritical EGS (SEGS) is ongoing, such as Iceland's IDDP projects (Reinsch et al. 2017), the Japan Beyond-Brittle Project (Muraoka et al. 2014), and the DESCRAMBLE project in Italy (Bertani et al. 2018). SEGSs involve drilling deeper into regions of partial melt past the brittle-ductile transition zone to achieve a larger flow temperature at the bottom of the wellbore (Cladouhos et al. 2018). Here, the fluid is expected to reach a supercritical state, with no clear distinction between the liquid and vapour phases; for pure water, this corresponds to temperature and pressure conditions above approximately $T=374{ }^{\circ} \mathrm{C}$ and $P=22.1 \mathrm{MPa}$ (Sudarmadi et al. 2012; Dobson et al. 2017). The development of SEGSs relies on ultra-high-temperature technology, capable of withstanding bottomhole temperatures of $430-550{ }^{\circ} \mathrm{C}$, typical of supercritical environments ( $\mathrm{Lu} 2018$ ). The IDDP-1 well yielded superheated steam at a temperature of $452{ }^{\circ} \mathrm{C}$ and pressure of $140 \mathrm{bar}$, corresponding to an electricity generation potential of $35 \mathrm{MWe}$, while in 2017, the IDDP-2 successfully reached supercritical fluids at $426^{\circ} \mathrm{C}$ and 340 bar at a depth of $4659 \mathrm{~m}$ (DEEPEGS 2018). However, IDDP-1 drilling was abandoned after hitting a magma intrusion at $900^{\circ} \mathrm{C}$ at $2100 \mathrm{~m}$ and the first flow test of IDDP-2, conducted in December 2019, encountered delays (DEEPEGS 2018, 2019). Overcoming the challenges posed by these unique resources could potentially unlock a five times greater energy content and a factor of ten times electricity generation potential associated with supercritical fluids at $400{ }^{\circ} \mathrm{C}$ compared with EGS technology at $200{ }^{\circ} \mathrm{C}$ (Cladouhos et al. 2018).

Before initiating an in-depth numerical investigation of unconventional designs into supercritical geothermal systems, this study presents a foundation for potential usage of this game-changing technology. In this study, an unconventional deep borehole heatexchanger (DBHE) design is accommodated into the NWG 55-29 open-loop well, to investigate its energy performance and potential usage for EGS projects in subcritical environments. It could also aid the development of unconventional designs in supercritical environments when a much greater depth is required-see Borehole settings in Newberry field for details on the current case study investigated. 
The conventional BHE design was conceived for shallow depths and low-temperature gradients, for heating and cooling applications (Acuña et al. 2011; Beier et al. 2013; Holmberg et al. 2016). Some DBHE sites already exist, including two deep boreholes in Weissbad and Weggis in Switzerland, at depths of $1.2 \mathrm{~km}$ and $2.3 \mathrm{~km}$, respectively (Kohl et al. 2000, 2002).

The modelled DBHE involves pumping cold fluid down the outer annulus, such that hot fluid rises to surface up the inner tubing via a thermosiphon effect (natural convection) or through the use of pumps (Tang et al. 2019). The DBHE design was previously modelled in the Villafortuna abandoned oil well in Italy (Alimonti et al. 2016), the KTB deep borehole project setting in Germany (Falcone et al. 2018), and the IDDP-1 well in Iceland (Renaud et al. 2019). Replacing the current NWG 55-29 well with a DBHE would not only mitigate the risks of induced seismicity, but also prevent fluid losses and contamination to the surrounding environment, as the working fluid is not in direct contact with the surrounding rock (Wang et al. 2019). Installation costs can also be reduced by decreasing the boreholes thermal resistance via a thermally enhanced outer pipe in ground-coupled heat pump systems (Raymond et al. 2015). A heat-conducting filler of graphite could also be implemented around the DBHE design to enhance downhole heat transfer (Falcone et al. 2018).

Former DBHE studies have relied upon numerical or analytical methods to discretise the geothermal system into elements within a grid (Alimonti et al. 2018). A research code T2Well/EOS1, recently developed at Lawrence Berkeley National Laboratory for simulating coupled wellbore-reservoir processes involved in geothermal systems, was adopted in this study to model appropriate subcritical conditions in the Newberry volcano area.

\section{Borehole settings in Newberry field}

This study focuses on the Newberry Volcano EGS project in Central Oregon. This site was one of the first to consider heat extraction from a volcanic source, in addition to developments in hydroshearing stimulation techniques to mitigate induced seismicity and adapting a thermally degradable zonal isolation material to isolate fractures from intended stimulated zones (Cladouhos et al. 2016). Figure 1 shows the two wellbore locations-NWG 55-29 and NWG 46-16-along the western flank of the volcano.

From Fig. 1, the NWG 55-29 was drilled down to $3067 \mathrm{~m}$ with a bottom well temperature of $331^{\circ} \mathrm{C}$ (Cladouhos et al. 2016), at subcritical conditions $\left(100{ }^{\circ} \mathrm{C}<T<374{ }^{\circ} \mathrm{C}\right.$ and $0.1 \mathrm{MPa}<P<22.1 \mathrm{MPa}$ ) (Asl and Khajenoori 2013), and plans to deepen the NWG 46-16 well to $4877 \mathrm{~m}$ are in place to transition into supercritical environments (Cladouhos et al. 2018). It is important to note that the wells NWG 55-29 and NWG 46-16 are openloop designs whereby the pumped working fluid is in direct contact with the reservoir.

A low average flow rate of $3.2 \mathrm{~kg} / \mathrm{s}$ was obtained from an NWG 55-29 stimulation test, compared to expected conventional EGS flow rates of $50-60 \mathrm{~kg} / \mathrm{s}$ (Cladouhos et al. 2016; MIT 2006). As a result of this and of the potential risk of induced seismicity, the DBHE design was chosen for this study. To ensure realistic wellbore properties for the synthetic DBHE in the Newberry settings, casing radii dimensions from existing sites defined previously (Weissbad and Weggis) were applied in this study. See "Sensitivity analysis" section for details. 


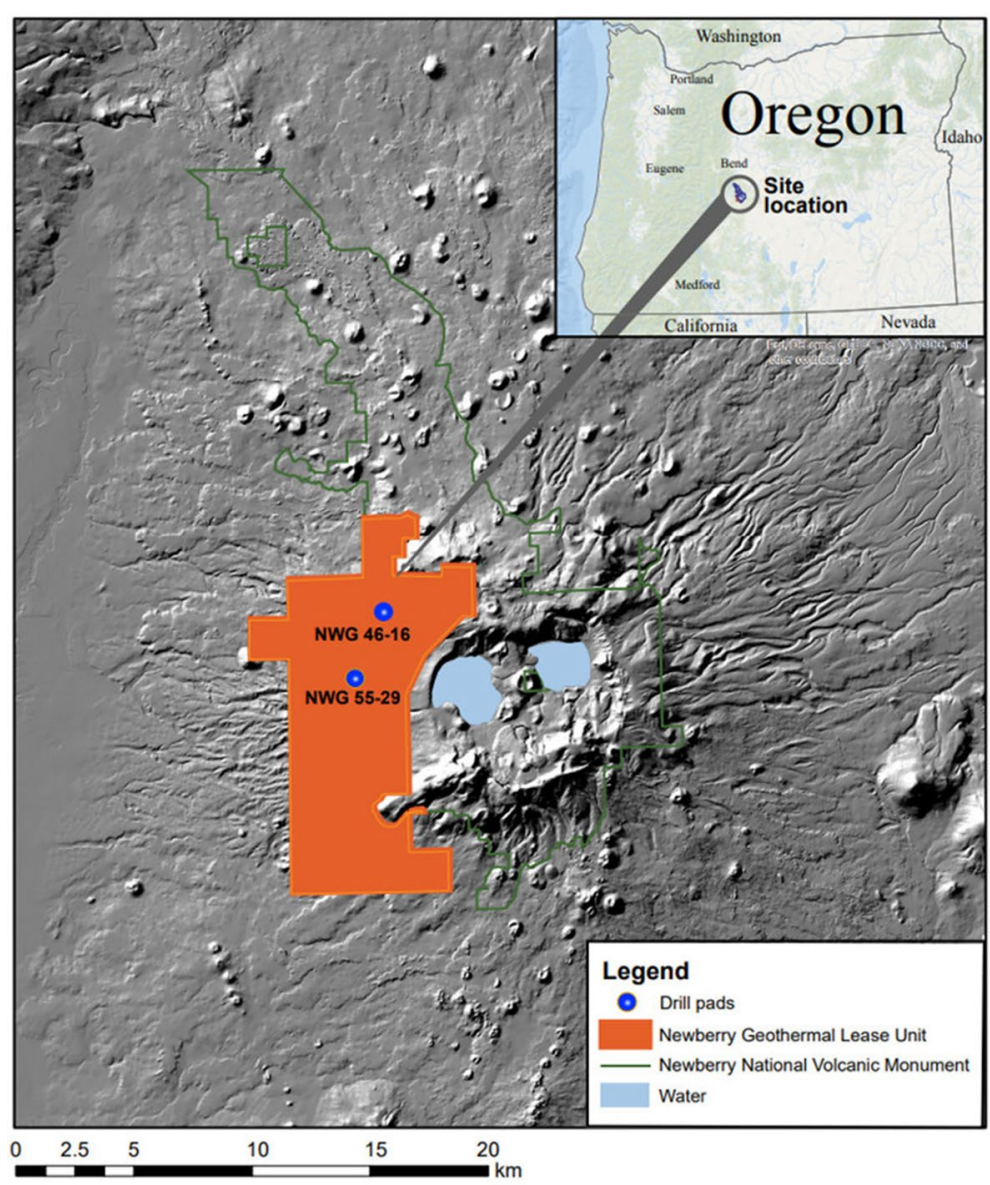

Fig. 1 NDDP site. NWG 46-16 and NWG 55-29 wellbore locations (Bonneville et al. 2018)

\section{Methods}

The DBHE was modelled into the Newberry geothermal system with a 2D axisymmetric MESH adopting T2Well/EOS1 (Pan and Oldenburg 2014). The model setup is described below.

\section{Mathematical model}

T2Well/EOS1 is an integrated wellbore-reservoir numerical simulator to simulate nonisothermal flows of multi-phase fluids (steam-water) in both domains simultaneously (Pruess et al. 2012). T2Well was previously used to model various contexts, such as heat extraction in a closed-loop system with supercritical $\mathrm{CO}_{2}$ as the working fluid (Higgins et al. 2016) and for a gas storage blow out (Pan et al. 2018). The equation of state (EOS1) was utilised, representing one non-isothermal water component under two-phase conditions (Pruess et al. 2012). The applied thermodynamic equations within the reservoir are similar to those used in other TOUGH2 family code and are defined in Table 1.

Equation (1) depicts the general mass and energy conservation equation with $M^{\mathrm{m}}, F^{\mathrm{m}}$, $M^{\mathrm{E}}$, and $F^{\mathrm{E}}$ in Eqs. (2)-(5) representing the mass accumulation, mass flux, energy accumulation, and energy flux terms, respectively (Renaud et al. 2020). The phase velocity 


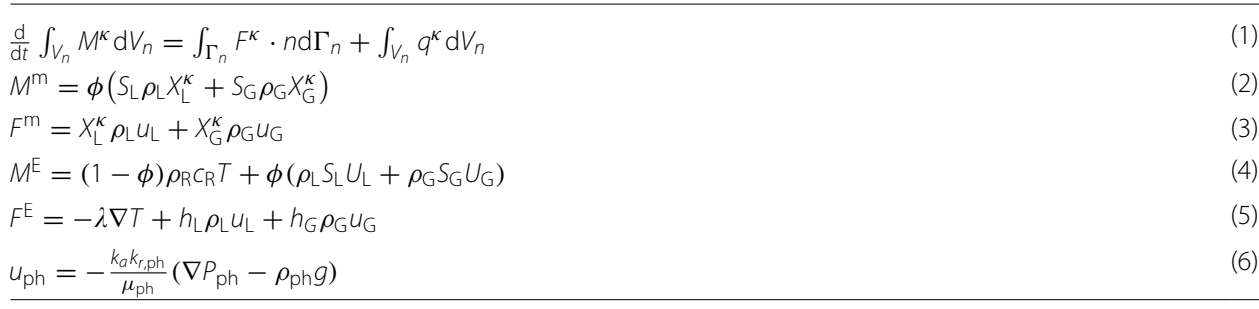

Table 2 Key wellbore equations

$\frac{\partial M^{\kappa}}{\partial t}=q^{\kappa}+F^{\kappa}$
$M^{E}=\rho\left\llcorner S_{L}\left(U_{L}+\frac{u_{L}^{2}}{2}+g z \cos \theta\right)+\rho_{G} S_{G}\left(U_{G}+\frac{u_{G}^{2}}{2}+g z \cos \theta\right)\right.$
$F^{E}=-\lambda \frac{\partial T}{\partial z}-\frac{1}{\sigma} \frac{\partial}{\partial z}\left[\sigma \rho_{L} S_{L} u_{L}\left(h_{L}+\frac{u_{L}^{2}}{2}+g z \cos \theta\right)+\sigma \rho_{G} S_{G} u_{G}\left(h_{G}+\frac{u_{G}^{2}}{2}+g z \cos \theta\right)\right]$

$u_{\mathrm{ph}}$ in Eq. (6) is solved by adopting a 3D multi-phase Darcy flow for a heterogeneous porous media.

The key equations for the wellbore used in T2Well/EOS1 are defined in Table 2. Equation (7) depicts the conservation equation in partial derivative form, with $M^{\mathrm{E}}$ defined in Eq. (8) and $F^{\mathrm{E}}$ in Eq. (9) representing the energy accumulation and flux terms, respectively (Renaud et al. 2020).

The drift-flux model (DFM) is used in solving the two-phase momentum conservation equation in the wellbore. A relationship is assumed between the gas velocity $\left(u_{\mathrm{G}}\right)$ and the volumetric flux of the mixture $(j)$ :

$$
u_{\mathrm{G}}=C_{0} j+u_{\mathrm{d}} .
$$

The liquid velocity $u_{\mathrm{L}}$ can then be calculated from $j$ and the drift velocity $u_{\mathrm{d}}$ as:

$$
u_{\mathrm{L}}=\frac{1-S_{\mathrm{G}} C_{0}}{1-S_{\mathrm{G}}} j-\frac{S_{\mathrm{G}}}{1-S_{\mathrm{G}}} u_{\mathrm{d}}
$$

The drift velocity is thus calculated as (Pan et al. 2005):

$$
u_{\mathrm{d}}=\frac{\left(1-C_{0} S_{\mathrm{G}}\right) u_{\mathrm{c}} K\left(S_{\mathrm{G}}, K_{u}, C_{0}\right) m(\theta)}{C_{0} S_{\mathrm{G}} \sqrt{\rho_{\mathrm{G}} / \rho_{\mathrm{L}}}+1-C_{0} S_{\mathrm{G}}} .
$$

The velocities $u_{\mathrm{G}}$ and $u_{\mathrm{L}}$ within the mixture are then solved with $u_{\mathrm{d}}$ to obtain the momentum conservation equation; simplified to Eq. (13) (Pan et al. 2011; Akbar et al. 2016):

$$
\frac{\partial}{\partial t}\left(\rho_{\mathrm{m}} u_{\mathrm{m}}\right)+\frac{1}{\sigma} \frac{\partial}{\partial z}\left[\sigma\left(\rho_{\mathrm{m}} u_{\mathrm{m}}^{2}+\gamma\right)\right]=-\frac{\partial P}{\partial z}-\frac{\Gamma f \rho_{\mathrm{m}}\left|u_{\mathrm{m}}\right| u_{\mathrm{m}}}{2 \sigma}-\rho_{\mathrm{m}} g \cos \theta
$$

Table 3 defines the remaining parameters from the drift-flux model, extracted from Pan and Oldenburg (2014). The mass and energy conservation equations are solved using the Newton-Raphson iteration process (Pruess et al. 2012). 
Table 3 Key drift-flux parameters in Eq. (13)

\begin{tabular}{ll}
\hline Description & Equation \\
\hline Slip between two phases & $\gamma=S_{\mathrm{G}}\left(\rho_{\mathrm{G}} \rho_{\llcorner} \rho_{\mathrm{m}} / \rho_{\mathrm{m}}^{* 2}\right)\left[\left(C_{0}-1\right) u_{\mathrm{m}}+u_{\mathrm{d}}\right]^{2} /\left(1-S_{\mathrm{G}}\right)$ \\
Mixture density & $\rho_{\mathrm{m}}=S_{\mathrm{G}} \rho_{\mathrm{G}}+\left(1-S_{\mathrm{G}}\right) \rho_{\mathrm{L}}$ \\
Mixture velocity & $u_{\mathrm{m}}=\left[S_{\mathrm{G}} \rho_{\mathrm{G}} u_{\mathrm{G}}+\left(1-S_{\mathrm{G}}\right) \rho_{\llcorner} u_{\llcorner}\right] / \rho_{\mathrm{m}}$ \\
Adjusted average density of mixture & $\rho_{\mathrm{m}}^{*}=S_{\mathrm{G}} C_{0} \rho_{\mathrm{G}}+\left(1-S_{\mathrm{G}} C_{0}\right) \rho_{\llcorner}$ \\
\hline
\end{tabular}

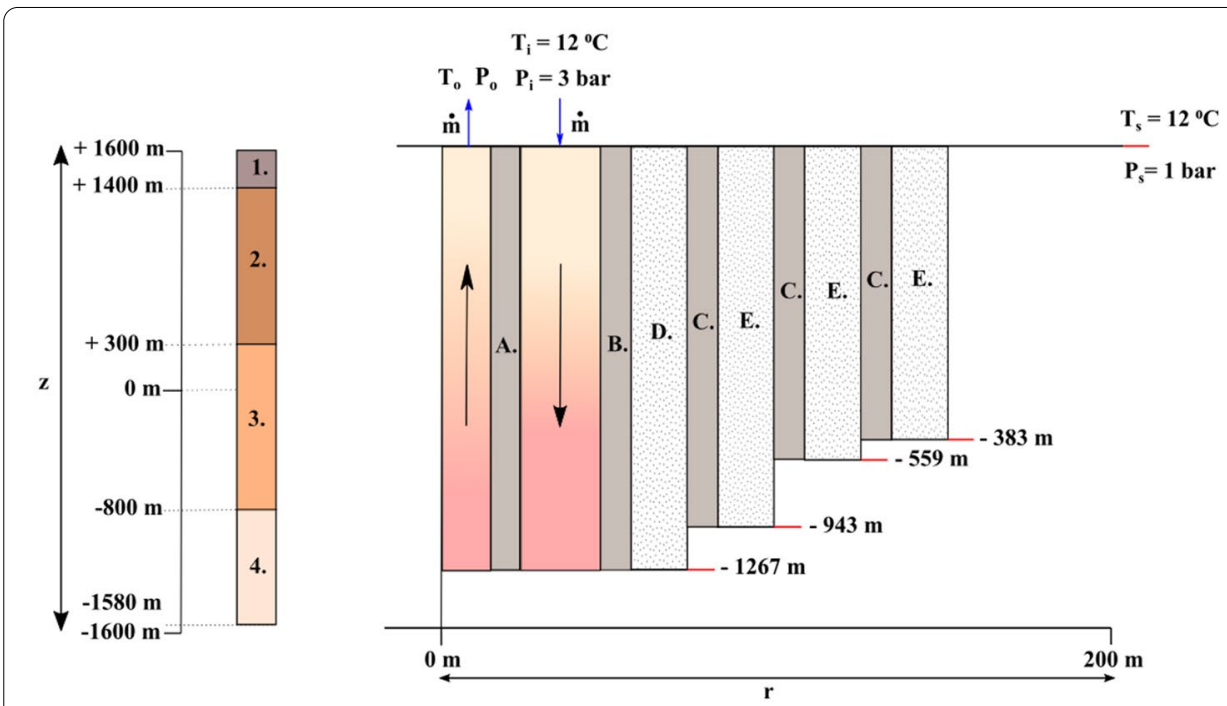

Fig. 2 Geological setting and well completion diagram of DBHE design implemented in T2Well/EOS1. Leftgeological setup, with four key zones at defined depths in the $z$ axis (+ $1599.50 \mathrm{~m}$ to $-1580 \mathrm{~m}$ ). Numbered labels are supported by thermodynamic properties in Table 4. Right-2D asymmetric scheme containing 2752 cells in the $r(1-200 \mathrm{~m}$ ) and $z$ axis, interpreted from Morita et al. (1992a), Sonnenthal et al. (2012). Well completion diagram of the DBHE interpreted from Cladouhos et al. (2016). Both depict the casing and cement sections at appropriate elevations in T2Well/EOS1, interpreted from Tang et al. (2019), Toth (2015)

\section{Newberry case study}

The DBHE was modelled into the Newberry geothermal system by replacing the NWG 55-29 well with the unconventional closed-loop design. The DBHE model built with T2Well/EOS1 is based on an experimental study from Morita et al. (1992b), whereby the measured and computed pressure and temperature values were verified with the HGP-A well site in Hawaii (Morita et al. 1992b). The original completion diagram from Morita et al. (1992b) was altered to account for the increase in depth from $879.5 \mathrm{~m}$ to the NWG 55-29 wellbore depth of $3067 \mathrm{~m}$ (Cladouhos et al. 2016). A 2D axisymmetric grid representation of the design is presented in Fig. 2; note that Casg1(A.) is the inner casing separating the outer annulus and the inner tubing and Casg2(B.) is the external casing separating the outer annulus and the cement, Ceme1(D.). Figure 2 highlights key elevation depths for each section to account for these changes. The bottom of the well reached an elevation of $-1267 \mathrm{~m}$.

The Newberry geothermal area was defined according to the thermal-hydrological-chemical model adopted from Sonnenthal et al. (2012). Four geological zones are highlighted in Fig. 2 with their thermodynamic properties in Table 4, obtained from 
Table 4 Key geological settings in support of Fig. 2 (left)

\begin{tabular}{|c|c|c|c|}
\hline Key & Geological name & Altitude range & Thermodynamic properties \\
\hline 1. & Newberry-Deschutes (upper) & $+1600 m$ to $+1400 m$ & $\begin{array}{l}\rho=2700 \mathrm{~kg} / \mathrm{m}^{3 \mathrm{~b}} \\
\mathrm{Cp}=1000 \mathrm{~J} / \mathrm{kg}^{\circ} \mathrm{C}^{\mathrm{b}} \\
\Phi=0.2(20 \%) \\
K=0.15 \times 10^{-11} \mathrm{~m}^{2} \\
\lambda=1.7 \mathrm{~W} / \mathrm{mK}\end{array}$ \\
\hline 2. & Newberry-Deschutes & $+1400 m$ to $+300 m$ & $\begin{array}{l}\Phi=0.1(10 \%) \\
K=0.1 \times 10^{-16} \mathrm{~m}^{2} \\
\lambda=1.8 \mathrm{~W} / \mathrm{mK}\end{array}$ \\
\hline 3. & John Day & $+300 m$ to $-800 m$ & $\begin{array}{l}\Phi=0.05(5 \%) \\
K=2.6 \times 10^{-16} \mathrm{~m}^{2} \\
\lambda=2.15 \mathrm{~W} / \mathrm{mK}\end{array}$ \\
\hline 4. & Intruded John Day & $-800 m$ to $-1500 m$ & $\begin{array}{l}\Phi=0.03(3 \%) \\
K=0.5 \times 10^{-17} \mathrm{~m}^{2} \\
\lambda=2.15 \mathrm{~W} / \mathrm{mK}\end{array}$ \\
\hline
\end{tabular}

a All properties apart from $\rho$ and $c_{p}$ are cited from Sonnenthal et al. (2012)

b All rock properties have identical $\rho$ and $c_{p}$ variables, quoted from Sammel et al. (1988)

Table 5 Key borehole properties in support of Fig. 2 (right)

\begin{tabular}{|c|c|c|c|}
\hline Key & Borehole section & Name of section & Thermodynamic properties \\
\hline A. & Insulated inner pipe & Casg1 & $\begin{array}{l}\rho=2700 \mathrm{~kg} / \mathrm{m}^{3} \\
\mathrm{C}_{\mathrm{p}}=470 \mathrm{~J} / \mathrm{kg}^{\circ} \mathrm{C} \\
\Phi=0(0 \%) \\
K=0 \mathrm{~m}^{2} \\
\lambda=0.01038 \mathrm{~W} / \mathrm{mK}^{\mathrm{a}}\end{array}$ \\
\hline B./C. & Casing & Casg2/Casg3 & $\begin{array}{l}\rho=2700 \mathrm{~kg} / \mathrm{m}^{3} \\
\mathrm{C}_{p}=470 \mathrm{~J} / \mathrm{kg}^{\circ} \mathrm{C} \\
\Phi=0(0 \%) \\
K=0 \mathrm{~m}^{2} \\
\lambda=46.1 \mathrm{~W} / \mathrm{mK}\end{array}$ \\
\hline D./E. & Cement & Ceme1/Ceme2 & $\begin{array}{l}\rho=1830 \mathrm{~kg} / \mathrm{m}^{3} \\
\mathrm{CP}=1900 \mathrm{~J} / \mathrm{kg}^{\circ} \mathrm{C} \\
\Phi=0(0 \%) \\
K=0 \mathrm{~m}^{2} \\
\lambda=0.99 \mathrm{~W} / \mathrm{mK}\end{array}$ \\
\hline
\end{tabular}

${ }^{a}$ Insulated inner casing, sourced from Falcone et al. (2018). Other parameters sourced from Morita et al. (1992a)

Sammel et al. (1988), Sonnenthal et al. (2012). Thermodynamic wellbore properties are also defined in Table 5, incorporated from Morita et al. (1992a), Falcone et al. (2018).

Referring to Fig. 2, water was injected into the outer annulus at a temperature of 12 ${ }^{\circ} \mathrm{C}$ with an imposed mass flow rate $\dot{m}$. The top boundary condition of the reservoir model was set with a surface temperature of $12{ }^{\circ} \mathrm{C}$ and a surface atmospheric pressure of 1 bar (Sonnenthal et al. 2012). As shown in Sonnenthal et al. (2012), it was assumed in the model that the surface pressure and temperature values were constant at elevation $+1600 \mathrm{~m}$, neglecting the pressure and thermal losses in the water table defined between +1800 and $+1600 \mathrm{~m}$. The default pressure for the boundary condition on the DBHE was set to 3 bar (as shown by $P_{\mathrm{i}}$ ) to prevent effects from local vacuum conditions reaching the lower limit of the code. Only heat flow was considered between the wellbore and reservoir to reflect the closed-loop design, excluding fluid flow. 


\section{T2Well numerical validation}

\section{Experimental validation}

The experimental data from a DBHE in Hawaii set at the depth of $879.6 \mathrm{~m}$ were used to validate the T2Well model (Morita et al. 1992b). The pressure and temperature distribution in the first $12 \mathrm{~h}$ showed a good match between measured values and simulations, as illustrated in Fig. 3. Model properties and details can be found in Renaud et al. (2020).

\section{Numerical discussion}

A DBHE with graphite on the wellbore was numerically investigated using FEFLOW (Falcone et al. 2018). While authors in Falcone et al. (2018) used constant water properties, T2Well uses the pressure- and temperature-dependent thermophysical properties based on models suggested by the International Formulation Committee (IFC 1967). As stated in Tang et al. (2019), Sui et al. (2019), constant fluid properties seem to generate errors in the pressure losses calculation and heat produced in DBHEs. The produced water temperature and heat flux were underestimated for a DBHE of $6100 \mathrm{~m}$ (Alimonti and Soldo 2016) and overestimated by $11 \%$ in a DBHE of $3500 \mathrm{~m}$ (Hu et al. 2020). These errors occurred due to not accounting for specific heat capacity and density changes within the DBHE. Compared with constant water properties, these changes would increase the total heat energy while decreasing the temperature of the return fluid.

The same deep geothermal system was modelled based on the KTB deep borehole project, reaching a reservoir depth of $8000 \mathrm{~m}$ (Falcone et al. 2018), using T2Well/EOS1. While a 3D model was considered in Falcone et al. (2018), the T2Well model used in this work is an axisymmetric RZ mesh centred on the wellbore. Graphite is implemented with a thermal conductivity value of $300 \mathrm{~W} / \mathrm{mK}$ and an assumed porosity of $1 \%$.

The T2Well grid contains 1030 elements. The maximum radial extension of the model is $1 \mathrm{~km}$. The bottom of the DBHE was set at a depth of $7000 \mathrm{~m}$. Water was injected in the annulus at the flow rate of $304.8 \mathrm{~m}^{3} /$ day $(\sim 7 \mathrm{~kg} / \mathrm{s})$. The reservoir was assumed to be fully saturated water. The surface temperature was set to $15^{\circ} \mathrm{C}$, with an initial temperature gradient of $40{ }^{\circ} \mathrm{C} / \mathrm{km}$. The bottom temperature is $330{ }^{\circ} \mathrm{C}$. The graphite filled
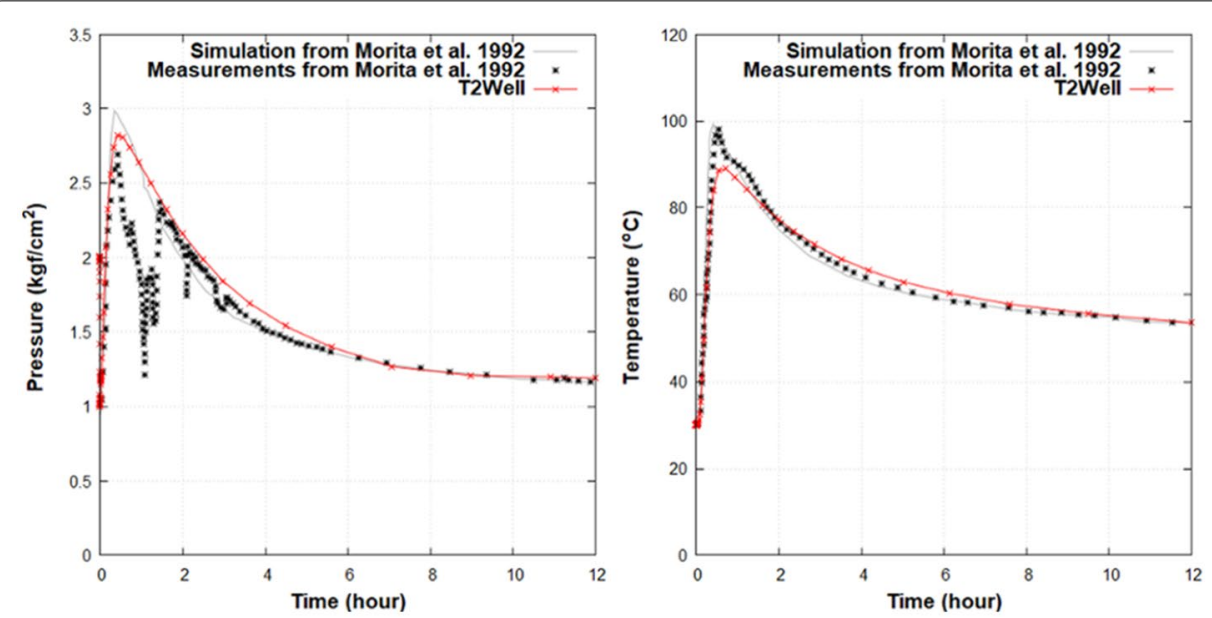

Fig. 3 Left-transient pressure simulation with T2Well compared to measurements from Morita et al. (1992). Right—-transient temperature simulation with T2Well compared to measurements from Morita et al. (1992) 
the surrounding of the DBHE from the depth of 4400 and $7200 \mathrm{~m}$ instead of the cement or grout. The value of casing materials is $900 \mathrm{~J} / \mathrm{kg} \mathrm{K}$ and the wall roughness is $2.5 \times 10^{-5}$ $\mathrm{m}$. The thermal properties of the rock and DBHE sections applied in the model can be found in Seyidov (2016), Falcone et al. (2018). Figure 4 describes the water temperature at the surface of the DBHE compared to the FEFLOW results.

From this case study, the temperature obtained at the surface of the DBHE was lower than previously described in Falcone et al. (2018), suggesting the potential overestimation of the water temperature using constant water properties due to changes in the specific heat value (Song et al. 2018). As stated by Hu et al. (2020), the temperaturedependent properties as calculated in T2Well/EOS1 must be considered for long-term performance evaluation of DBHE.

\section{Sensitivity analysis}

Table 6 summarises the parameters investigated in this study: mass flow rate of water $\dot{m}(\mathrm{~kg} / \mathrm{s})$, thermal conductivity $\lambda(\mathrm{W} / \mathrm{mK})$ of the casings and cement (see Fig. 2$)$, and the wellbore inner $r_{\mathrm{i}}(\mathrm{m})$ and outer $r_{\mathrm{o}}(\mathrm{m})$ radii dimensions for the annulus and tubing. All parameter changes were referenced against a base-case scenario from Morita et al. (1992b).

The working fluid velocity $u_{\mathrm{F}}$ at the bottom of the well was explored for values $3 \mathrm{~kg} / \mathrm{s}$ $<\dot{m}<9 \mathrm{~kg} / \mathrm{s}$ (see "Mass flow rate" section).

An insulated inner casing is advantageous for preventing heat losses between the inner tubing and the outer annulus, hence maximising the extracted energy flow rate at the outlet (Falcone et al. 2018; Song et al. 2018). Therefore, the effectiveness of an insulated inner casing as inner tubing for the DBHE was investigated by adjusting $\lambda(\mathrm{W} / \mathrm{mK})$ of Casg1, whilst $\dot{m}$ was fixed at $5 \mathrm{~kg} / \mathrm{s}$. Note $46.1 \mathrm{~W} / \mathrm{mK}$ was chosen as an upper limit to

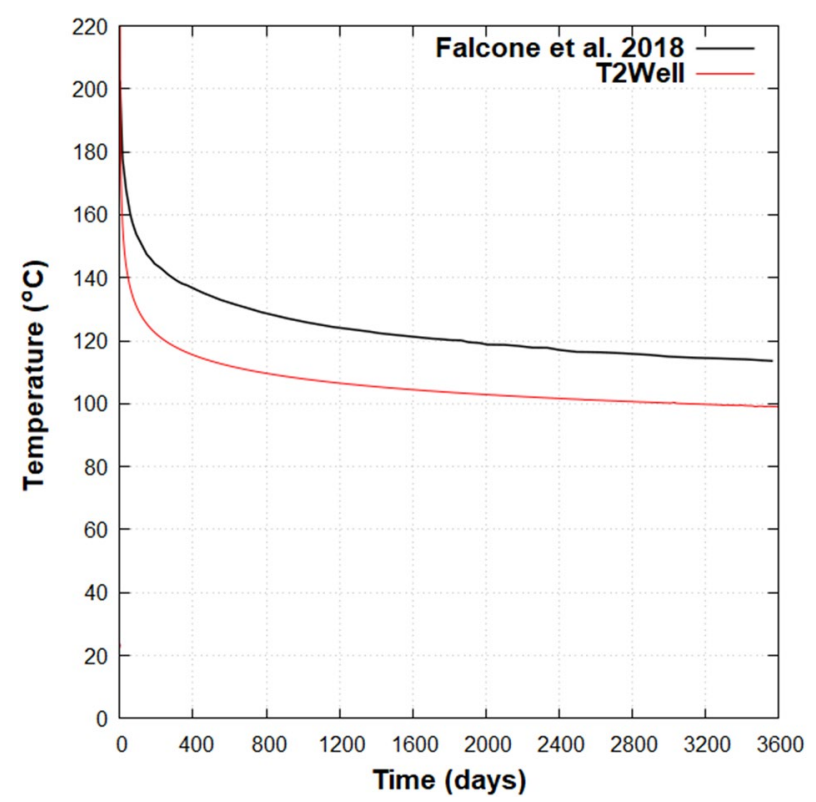

Fig. 4 Numerical results comparison from Falcone et al. (2018) and the T2Well/EOS1 model 
Table 6 Parameter changes investigated in the DBHE model

\begin{tabular}{|c|c|c|c|}
\hline Parameters & Values & Description & Base case \\
\hline$\dot{m}(\mathrm{~kg} / \mathrm{s})$ & $3-5-7-9$ & & 5 \\
\hline \multicolumn{4}{|l|}{ Inner casing properties } \\
\hline \multirow[t]{4}{*}{ Casg1 $\lambda(\mathrm{W} / \mathrm{mK})$} & 0.01038 & Insulated ${ }^{a}$ & \\
\hline & 1.163 & Morita $^{b}$ & 0.01038 \\
\hline & 2.5 & & \\
\hline & 46.1 & Morita $^{c}$ & \\
\hline \multicolumn{4}{|l|}{ Outer casing properties } \\
\hline \multirow[t]{4}{*}{ Casg2-3 $\lambda(\mathrm{W} / \mathrm{mK})$} & 46.1 & Morita $^{b}$ & \\
\hline & 45.0 & Weissbad $^{d}$ & 46.1 \\
\hline & 15.0 & Newberry ${ }^{e}$ & \\
\hline & 0.01038 & Insulated ${ }^{\mathrm{a}}$ & \\
\hline \multicolumn{4}{|l|}{ Cement properties } \\
\hline \multirow[t]{4}{*}{ Ceme1-2 $\lambda(\mathrm{W} / \mathrm{mK})$} & 0.99 & Morita $^{c}$ & \\
\hline & 2.24 & REF concrete ${ }^{f}$ & 0.99 \\
\hline & 3.52 & GRAP concrete ${ }^{f}$ & \\
\hline & 300 & Graphite flakes $^{\mathrm{a}}$ & \\
\hline \multicolumn{4}{|l|}{ Radii } \\
\hline \multirow[t]{5}{*}{ Annulus radii $r_{i} / r_{0}(m)$} & $0.0797 / 0.0889$ & Morita & \\
\hline & $0.0629 / 0.0721$ & Case1 & \\
\hline & $0.1061 / 0.1153$ & Case2 & $0.0797 / 0.0889$ \\
\hline & $0.0797 / 0.0889$ & Case3 & \\
\hline & $0.0797 / 0.0889$ & Case4 & \\
\hline \multirow[t]{5}{*}{ Tubing radii $r_{\mathrm{i}} / r_{\mathrm{o}}(\mathrm{m})$} & $0.0253 / 0.0445$ & Morita & \\
\hline & $0.0253 / 0.0445$ & Case1 & \\
\hline & $0.0253 / 0.0445$ & Case2 & $0.0253 / 0.0445$ \\
\hline & $0.0336 / 0.0528$ & Case3 & \\
\hline & $0.0173 / 0.0365$ & Case4 & \\
\hline \multicolumn{4}{|c|}{ a Insulated inner casing $0.01038 \mathrm{~W} / \mathrm{mK}$, cited from Falcone et al. (2018) } \\
\hline \multicolumn{4}{|c|}{ b Thermal conductivity values quoted from Morita et al. (1985) } \\
\hline \multicolumn{4}{|c|}{ c Thermal conductivity values quoted from Morita et al. (1992a) } \\
\hline \multicolumn{4}{|c|}{ d Weissbad parameters quoted from Kohl et al. (2000) } \\
\hline \multicolumn{4}{|c|}{ e Newberry parameters quoted from Cladouhos (2012) } \\
\hline f Cement parameters obta & di et al. (2018) & & \\
\hline
\end{tabular}

explore the heat transfer through the design when all three casing properties are identical-Casg $2=$ Casg 3 at $\lambda=46.1 \mathrm{~W} / \mathrm{mK}-$ (see "Inner casing properties" section).

Fixing Casg1 at $\lambda=0.01038 \mathrm{~W} / \mathrm{mK}$ and $\dot{m}=5 \mathrm{~kg} / \mathrm{s}$, the outer casing thermal conductivity $\lambda$ was adjusted based on quoted values in Table 6 . The casing properties extracted from the Weissbad DBHE and the NWG 55-29 well were explored here (see "Outer casing properties" section).

Fixing $\dot{m}$, Casg1 and Casg2 properties to the base-case values quoted in Table 6, the thermal conductivity $\lambda$ parameter for various cements was explored. The use of a heat conducting filler for enhanced heat transfer (graphite flakes positioned laterally and parallel to one another) was also investigated (Falcone et al. 2018) at $\lambda=300 \mathrm{~W} / \mathrm{mK}$ (see "Cement properties" section).

Four wellbore radii cases were investigated: annulus reduction (Case1), annulus increase (Case2), tubing increase (Case3), and tubing reduction (Case4) against the 
base-case radii dimensions from Morita et al. (1992b). Again, the mass flow rate was fixed at $\dot{m}=5 \mathrm{~kg} / \mathrm{s}$. Case 1 involved an annulus reduction by 1.27 , incorporating $r_{\mathrm{i}}=$ $0.0629 \mathrm{~m}$ from the Weggis plant (Kohl et al. 2002). Case2 involved an annulus increase by 1.33 by implementing $r_{\mathrm{i}}=0.1061 \mathrm{~m}$ from the Weissbad well (Kohl et al. 2000). Case3 values were chosen, so the tubing increase factor was equal to that of Case2 (1.33). Case4 tubing reduction by 1.22 was influenced by $r_{\mathrm{o}}=0.0365 \mathrm{~m}$ tubing dimension from the Weggis well (Kohl et al. 2002). For all radii changes, the annular space between $r_{\mathrm{i}}$ and $r_{\mathrm{o}}$ remained constant at $0.0092 \mathrm{~m}$ and $0.0192 \mathrm{~m}$ for the annulus and tubing, respectively. The cross-sectional area ratio between the annulus and tubing was also explored, by adopting Eqs. (14) and (15), respectively:

$$
\begin{aligned}
& \sigma_{\mathrm{A}}=\pi\left(r_{\mathrm{i}, \mathrm{A}}^{2}-r_{\mathrm{o}, \mathrm{T}}^{2}\right), \\
& \sigma_{\mathrm{T}}=\pi r_{\mathrm{i}, \mathrm{T}}^{2} .
\end{aligned}
$$

Here, $r_{\mathrm{i}, \mathrm{A}}$ is the inner annulus radii, $r_{\mathrm{O}, \mathrm{T}}$ is the outer tubing radii, and $r_{\mathrm{i}, \mathrm{T}}$ is the inner tubing radii. See "Radii" section for more details.

The heat transfer down the outer annulus and up the inner tubing was investigated for each parameter change and compared to the base-case scenario from Morita et al. (1992b), as shown in Table 6. For each parameter change, the temperature $T\left({ }^{\circ} \mathrm{C}\right)$ and pressure $\mathrm{P}(\mathrm{MPa})$ vs. elevation $(\mathrm{m})$ were investigated over a total simulation time of 30 years. In addition, the simulated energy flow rate of the wellbore $q_{\mathrm{Th}}(\mathrm{MW})$ was also extracted from the output file. A review on the energy flow rate for the closed-loop DBHE vs. open-loop NWG 55-29 wellbore was explored and concludes this study. The energy flow rate is estimated for the NWG 55-29 wellbore by adopting Eq. (16):

$$
q_{\mathrm{Th}}=c_{\mathrm{P}} \dot{m} \Delta T,
$$

where $\Delta T=T_{\mathrm{o}}-T_{\mathrm{i}}, T_{\mathrm{o}}=94{ }^{\circ} \mathrm{C}$ representing the first flow back temperature recorded at the outlet point of the NWG 55-29 wellbore (Cladouhos et al. 2016) and $T_{\mathrm{i}}=12$ ${ }^{\circ} \mathrm{C}$ is the surface temperature of the Newberry environment (Sonnenthal et al. 2012). $c_{\mathrm{P}}=4200 \mathrm{~J} / \mathrm{kg}^{\circ} \mathrm{C}$ is assumed a constant for pure water properties. See Energy flow rate comparison between DBHE and NWG 55-29 section for details.

\section{Results and Discussion}

\section{Mass flow rate}

Figure 5 shows the temperature and pressure distributions along the DBHE for varied $\dot{m}$. Table 7 highlights key thermodynamic properties from Fig. 5 and the simulation output file: $\Delta T$ between inlet $T_{\mathrm{i}}$ and outlet $T_{\mathrm{o}}$ points, energy flow rate $q_{\mathrm{Th}}$, and the working fluid velocity $u_{\mathrm{F}}$ at the bottom of the wellbore:

From Fig. 5, it appears that an increase in $\dot{m}$ results in a lower bottom well temperature $\left(32{ }^{\circ} \mathrm{C}\right.$ for $9 \mathrm{~kg} / \mathrm{s}$ in comparison to $73{ }^{\circ} \mathrm{C}$ for $\left.3 \mathrm{~kg} / \mathrm{s}\right)$. This decrease is observed in response to an increase in working fluid velocity $(4.42 \mathrm{~m} / \mathrm{s}$ vs. $1.51 \mathrm{~m} / \mathrm{s})$, leading to a shorter residence time. An increased $\dot{m}$ up the tubing results in a lower outlet temperature $\left(34.5{ }^{\circ} \mathrm{C}\right.$ for $9 \mathrm{~kg} / \mathrm{s}$ in comparison to $71.4{ }^{\circ} \mathrm{C}$ for $\left.3 \mathrm{~kg} / \mathrm{s}\right)$ 

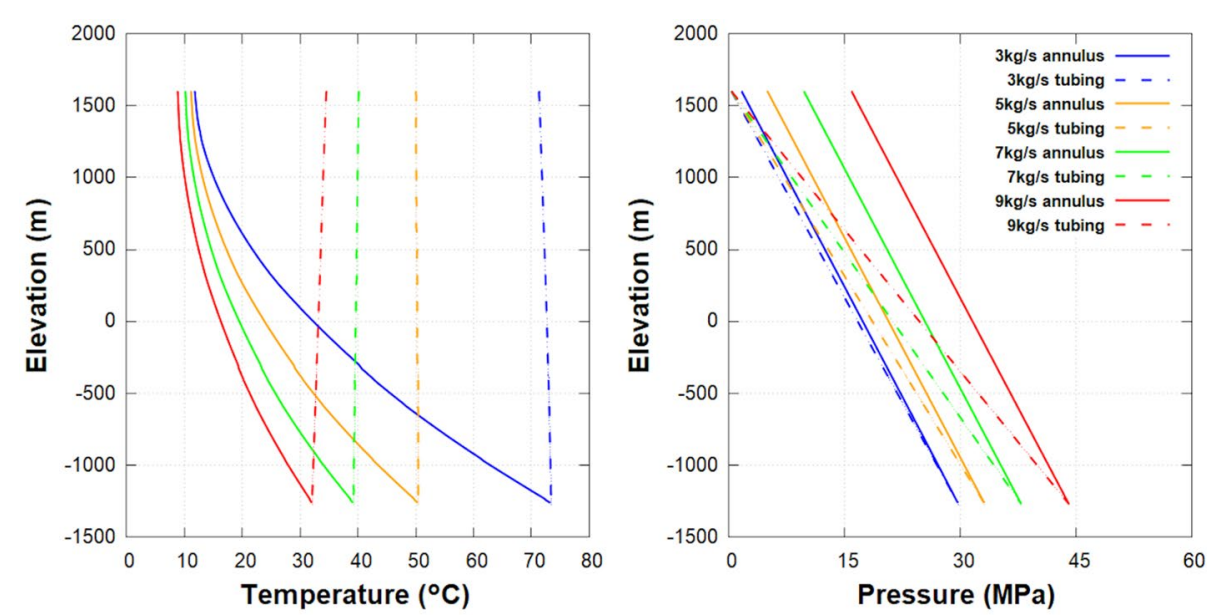

Fig. 5 Mass flow rate analysis over 30 years. Left-temperature vs. elevation for various $\dot{m}(\mathrm{~kg} / \mathrm{s})$. Rightpressure vs. elevation for various $\dot{m}(\mathrm{~kg} / \mathrm{s})$. Solid lines represent annulus and dashed lines tubing data, respectively. Legend applies to both graphs. All cases were compared with the base-case graph (in yellow)

Table 7 Key thermodynamic properties for various $\dot{m}(\mathrm{~kg} / \mathrm{s})$ quoted to three significant figures (3.s.f)

\begin{tabular}{llll}
\hline$\dot{\boldsymbol{m}}(\mathbf{k g} / \mathbf{s})$ & $\boldsymbol{\Delta} \boldsymbol{T}\left({ }^{\circ} \mathbf{C}\right)$ & $\boldsymbol{q}_{\mathbf{T h}}(\mathbf{M W})$ & $\boldsymbol{u}_{\mathbf{F}}(\mathbf{m} / \mathbf{s})$ \\
\hline 3 & 59.6 & 1.14 & 1.51 \\
5 & 38.9 & 1.46 & 2.48 \\
7 & 30.0 & 1.76 & 3.45 \\
9 & 25.7 & 2.06 & 4.42 \\
\hline
\end{tabular}

A slight gain in temperature up the tubing is also observed (a $2.48{ }^{\circ} \mathrm{C}$ increase for 9 $\mathrm{kg} / \mathrm{s}$ in comparison to a $2.06{ }^{\circ} \mathrm{C}$ decrease for $3 \mathrm{~kg} / \mathrm{s}$ ). This could be due to a higher pressure reduction up the tubing ( $\Delta P=43.7 \mathrm{MPa}$ for $9 \mathrm{~kg} / \mathrm{s} \mathrm{vs.} \Delta P=29.4 \mathrm{MPa}$ for $3 \mathrm{~kg} / \mathrm{s}$ ).

A mass flow rate value of $9 \mathrm{~kg} / \mathrm{s}$ displays the highest $q_{\mathrm{Th}}$ compared with $3 \mathrm{~kg} / \mathrm{s}$ and yields the largest $\Delta T$ up the tubing. Ideally, $\Delta T$ should be minimised up the tubing to enhance the systems efficiency by extracting more heat from the surrounding formations. A balance between efficiency and energy flow rate should be achieved. Due to 9 $\mathrm{kg} / \mathrm{s}$ causing too high of a friction loss up the tubing and inducing higher pumping costs as shown by an increased inlet pressure (15.9 MPa as opposed to $1.62 \mathrm{MPa}$ for $3 \mathrm{~kg} / \mathrm{s}$ ), and $3 \mathrm{~kg} / \mathrm{s}$ yielding the lowest energy flow rate $(1.14 \mathrm{MW}), 5 \mathrm{~kg} / \mathrm{s}$ is considered the bestcase scenario with minimal $\Delta T$ up the tubing and an energy flow rate of $q_{\mathrm{Th}}=1.46 \mathrm{MW}$.

\section{Inner casing properties}

Figure 6 shows the temperature and pressure distributions along the DBHE for varied $\lambda$ in Casg1. Table 8 summarises key thermodynamic properties extracted from Fig. 6 and from the simulation output file: $\Delta T$ between inlet $\left(T_{\mathrm{i}}\right)$ and outlet $\left(T_{o}\right)$ points and the energy flow rate $q_{\mathrm{Th}}$.

$\Delta T$ down the annulus is seen to increase, while $\lambda$ increases in Casg1 $(\Delta T=39.2$ ${ }^{\circ} \mathrm{C}$ for $\lambda=0.01038 \mathrm{~W} / \mathrm{mK}$ compared with $\Delta T=216{ }^{\circ} \mathrm{C}$ for $\lambda=46.1 \mathrm{~W} / \mathrm{mK}$ ). This is 

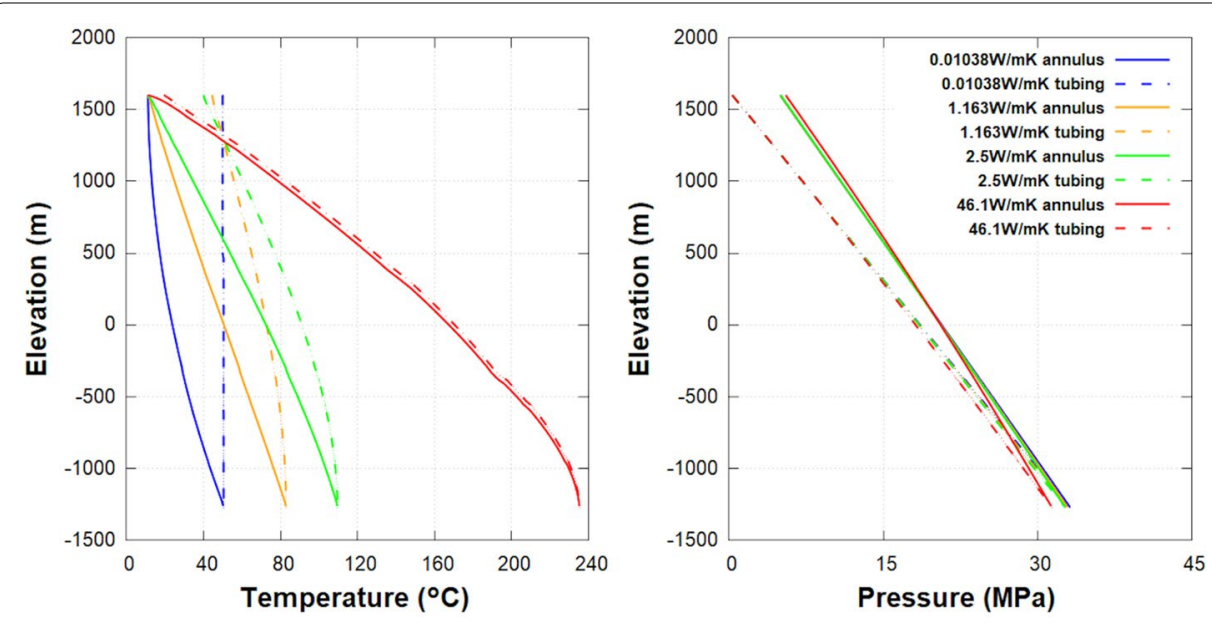

Fig. 6 Thermal conductivity analysis in inner casing (Casg1) over 30 years. Left-temperature vs. elevation for various $\lambda(\mathrm{W} / \mathrm{mK})$. Right-pressure vs. elevation for various $\lambda(\mathrm{W} / \mathrm{mK})$. Solid lines represent annulus and dashed lines represent tubing data, respectively. Legend applies to both graphs. All cases were compared to the base-case graph (in blue)

Table 8 Key thermodynamic properties for various $\lambda(\mathrm{W} / \mathrm{mK})$ quoted to 3.s.f

\begin{tabular}{|c|c|c|}
\hline$\lambda(\mathrm{W} / \mathrm{mK})$ & $\Delta T\left({ }^{\circ} \mathrm{C}\right)$ & $q_{\mathrm{Th}}(\mathrm{MW})$ \\
\hline 0.01038 & 38.9 & 1.46 \\
\hline 1.163 & 33.3 & 1.35 \\
\hline 2.5 & 28.8 & 1.25 \\
\hline 46.1 & 8.19 & 0.830 \\
\hline
\end{tabular}

in agreement with Fourier's law of heat conduction (Nuclear-power.net 2019) via an increase in heat transfer from the reservoir into the wellbore. The inlet pressure remains approximately constant at $5 \mathrm{MPa}$ due to the constant mass flow rate of $5 \mathrm{~kg} / \mathrm{s}$ imposed. In addition, the outlet pressure remains constant at $0.3 \mathrm{MPa}$. Using a thermal conductivity $\lambda>0.01038 \mathrm{~W} / \mathrm{mK}$, the temperature up the tubing significantly reduces as a result of low thermal insulation between the annulus and tubing (Song et al. 2018). For maximum efficiency, $\Delta T$ should be minimised to follow an isothermal process to surface. In fact, $\lambda=46.1 \mathrm{~W} / \mathrm{mK}$ is considered the worst-case scenario when all casing properties are identical and thermal insulation is at its lowest.

A higher $\lambda$ yields a smaller $\Delta T$ between the inlet and outlet points and hence a smaller energy flow rate $q_{\mathrm{Th}}(0.830 \mathrm{MW}$ vs. $1.46 \mathrm{MW})$, again due to poor thermal insulation. Therefore, minimising the thermal conductivity in Casg1 $(\lambda=0.01038 \mathrm{~W} / \mathrm{mK})$ is the best-case scenario to achieve maximal bottomhole $T$ and preventing significant cooling of the fluid up the tubing.

\section{Outer casing properties}

Figure 7 displays the temperature and pressure distributions along the DBHE for varied $\lambda$ in the outer casing. The first three parameter changes result in nearly identical temperature and pressure profiles. Therefore, two cases were compared: $\lambda=0.01038 \mathrm{~W} / \mathrm{mK}$ 

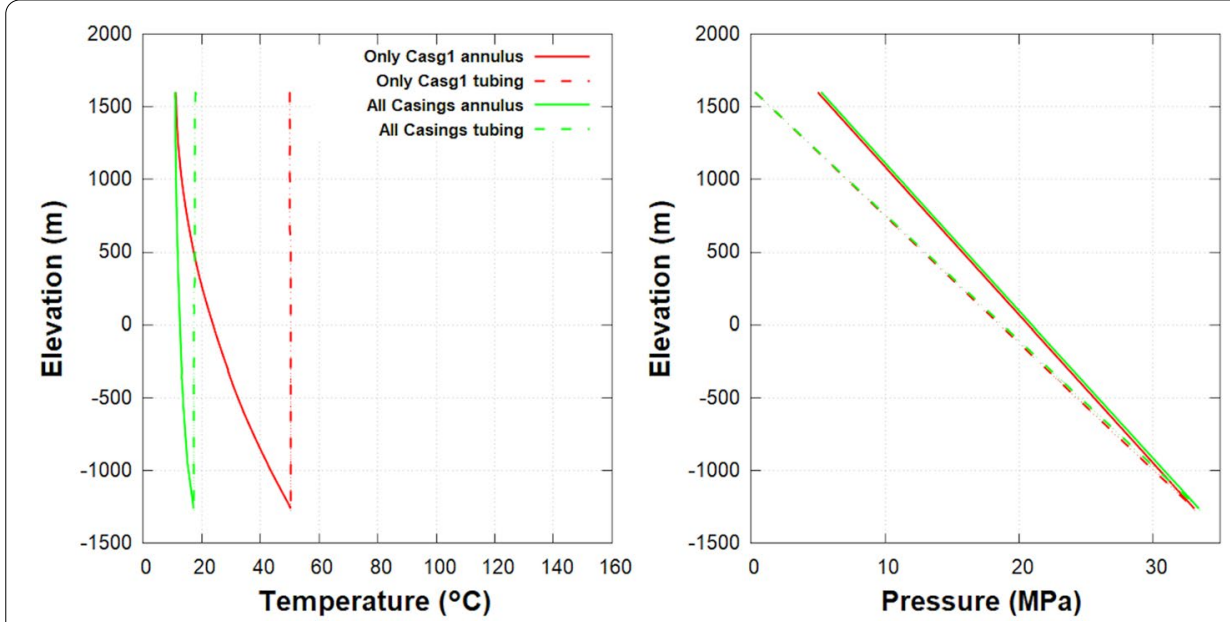

Fig. 7 Thermal conductivity analysis in outer casings for fixed $\dot{m}=5(\mathrm{~kg} / \mathrm{s})$ over 30 years. Left-temperature vs. elevation for various $\lambda(\mathrm{W} / \mathrm{mK})$. Right-pressure vs. elevation for various $\lambda(\mathrm{W} / \mathrm{mK})$. Solid lines represent annulus and dashed lines represent tubing data, respectively. The base-case graph here is highlighted in red

Table 9 Key results comparing insulating properties for only Casg1 and for all casings to 3.s.f

\begin{tabular}{lcc}
\hline Key results & Only Casg1 & All casings \\
\hline$T_{\mathrm{i}}\left({ }^{\circ} \mathrm{C}\right)$ & 11.1 & 10.9 \\
$T_{\mathrm{O}}\left({ }^{\circ} \mathrm{C}\right)$ & 50.0 & 17.8 \\
$\Delta T\left({ }^{\circ} \mathrm{C}\right)$ & 38.9 & 6.92 \\
$P_{\mathrm{i}}(\mathrm{MPa})$ & 4.97 & 5.23 \\
$P_{\mathrm{O}}(\mathrm{MPa})$ & 0.302 & 0.302 \\
$q_{\mathrm{Th}}(\mathrm{MW})$ & 1.46 & 0.785 \\
\hline
\end{tabular}

for the inner Casg1 only (red), and for all casings (green). Table 9 highlights key thermodynamic properties from Fig. 6 and the output file: $\Delta T$ between inlet $T_{\mathrm{i}}$ and outlet $T_{\mathrm{o}}$ points, the inlet $P_{\mathrm{i}}$ and outlet $P_{\mathrm{o}}$ pressure points and the simulated energy flow rate $q_{\mathrm{Th}}$ for these two cases.

When all casings are insulated at $\lambda=0.01038 \mathrm{~W} / \mathrm{mK}$, a lower bottomhole temperature $\left(17.2^{\circ} \mathrm{C}\right.$ vs. $\left.50.4{ }^{\circ} \mathrm{C}\right)$ is observed in addition to a lower outlet temperature $\left(T_{\mathrm{o}}=17.8\right.$ ${ }^{\circ} \mathrm{C}$ vs. $T_{\mathrm{O}}=50.0^{\circ} \mathrm{C}$ ). This is due to insufficient heat transfer between the reservoir and wellbore. $\Delta T$ between the inlet and outlet points decreases approximately by a factor of $6\left(6.92^{\circ} \mathrm{C}\right.$ vs. $\left.38.9^{\circ} \mathrm{C}\right)$ and hence results in a reduction in $q_{\mathrm{Th}}(0.785 \mathrm{MW}$ vs. $1.46 \mathrm{MW})$ as the water fails to gain significant temperature down the annulus when all casings are insulated. Therefore, to ensure an efficient thermal recovery, the best-case scenario is observed when only the inner casing is insulated at $\lambda=0.1038 \mathrm{~W} / \mathrm{mK}$ compared to all casing. This is because Casg1 is most sensitive to $\Delta T$ up the tubing-as seen in "Mass flow rate" section above.

\section{Cement properties}

Figure 8 shows the temperature and pressure distributions along the DBHE for varied $\lambda$ cement properties (Ceme 1 and Ceme 2 in Fig. 2). Key thermodynamic 

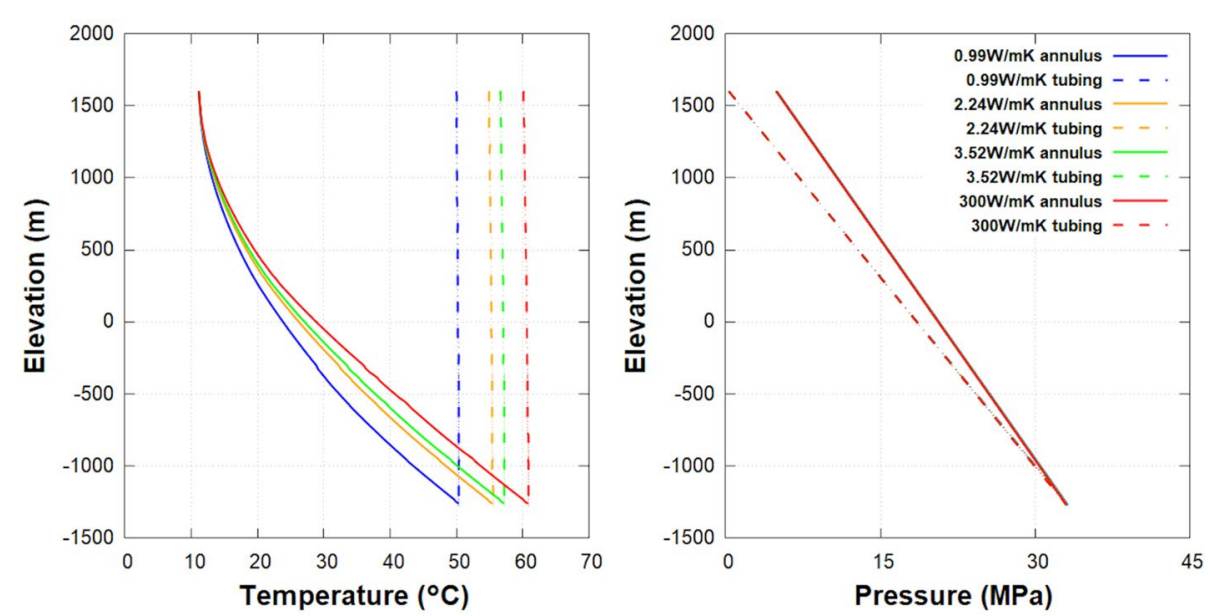

Fig. 8 Thermal conductivity analysis in cement layers for fixed $\dot{m}=5(\mathrm{~kg} / \mathrm{s})$ over 30 years. Lefttemperature vs. elevation for various $\lambda(\mathrm{W} / \mathrm{mK})$. Right—pressure vs. elevation for various $\lambda(\mathrm{W} / \mathrm{mK})$. Solid lines represent annulus and dashed lines represent tubing data, respectively. Legend applies to both graphs. The base-case graph here is highlighted in blue

Table 10 Key thermodynamic properties for various $\lambda(\mathrm{W} / \mathrm{mK})$ to 3.s.f

\begin{tabular}{lll}
\hline $\boldsymbol{\lambda}(\mathbf{W} / \mathrm{mK})$ & $\boldsymbol{\Delta} \boldsymbol{T}\left({ }^{\circ} \mathbf{C}\right)$ & $\boldsymbol{q}_{\mathrm{T}}(\mathbf{M W})$ \\
\hline 0.99 & 38.9 & 1.46 \\
2.24 & 43.8 & 1.57 \\
3.52 & 45.5 & 1.60 \\
300 & 49.0 & 1.67 \\
\hline
\end{tabular}

properties extracted from Fig. 8 and from the simulation output file are summarised in Table 10: $\Delta T$ between inlet $T_{\mathrm{i}}$ and outlet $T_{\mathrm{o}}$ points, and the simulated energy flow rate $q_{\mathrm{Th}}$.

The bottomhole temperature down the annulus increases from 50.4 to $60.9{ }^{\circ} \mathrm{C}$ for $\lambda=0.99 \mathrm{~W} / \mathrm{mK}$ and $\lambda=300 \mathrm{~W} / \mathrm{mK}$ respectively. Hence, $T_{\mathrm{o}}$ increases as a result of an increase in $\lambda$ within the cement, suggesting that this parameter change enhances the amount of heat transfer between the reservoir and working fluid. In particular, this heat transfer is hindered when $\lambda$ is lower than that of the reservoir, as identified in Song et al. (2018). As $\lambda$ predominantly affects $T$ and not $P$ (as seen in "Inner casing properties" section), the pressure distribution along the DBHE shows similar results for all parameter changes. Referring to Table $10, \lambda$ is maximised in conjunction with $q_{\mathrm{Th}}$, with a percentage increase of $14.4 \%$ comparing conventional cement with a graphite heat conductive filler (1.67 MW for $\lambda=0.99 \mathrm{~W} / \mathrm{mK}$ vs. $1.46 \mathrm{MW}$ for $\lambda=300 \mathrm{~W} / \mathrm{mK}$ ). While the use of graphite significantly empowers the heat transfer in the DBHE design, its use as a cement additive is an unproved concept. Therefore, $\lambda<3.52 \mathrm{~W} / \mathrm{mK}$ parameters are deemed more reasonable as best-case scenarios, because conventional cement falls into the region of $0.2<\lambda<3.63 \mathrm{~W} / \mathrm{mK}$ (Ichim et al. 2016). 

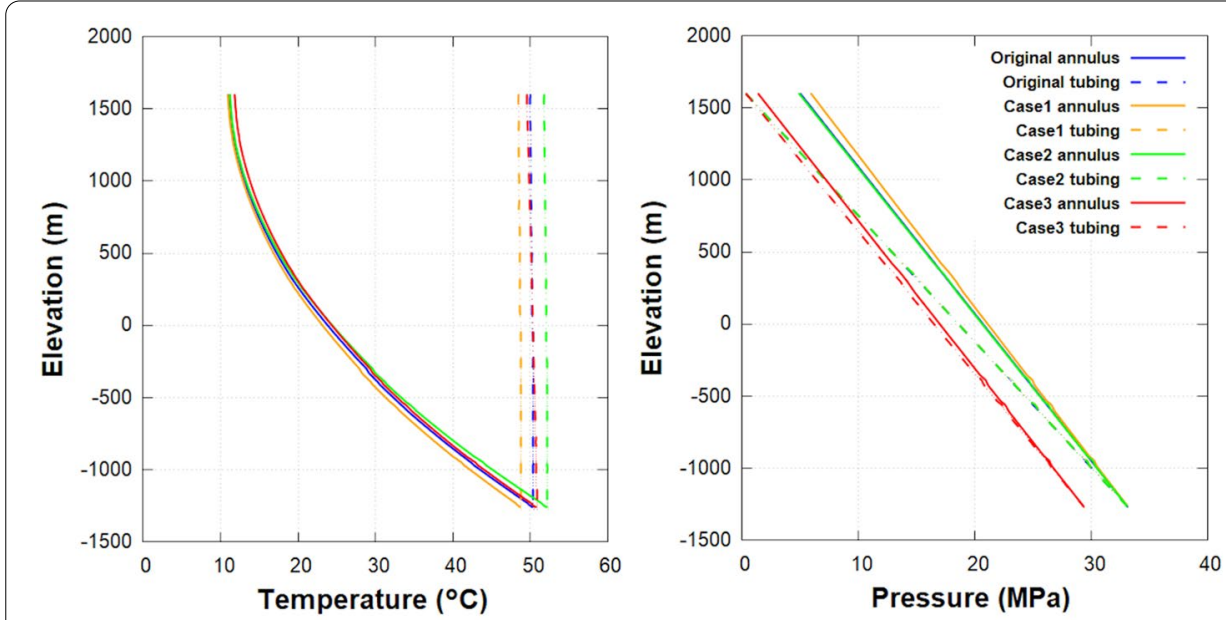

Fig. 9 Radii analysis for fixed $\dot{m}=5$ (kg/s) over 30 years. Left-temperature vs. elevation for the original, annulus reduction (Case1), annulus increase (Case2), and tubing increase (Case3). Right-pressure vs. elevation for the same cases. Solid lines represent annulus and dashed lines represent tubing data, respectively. Legend applies to both graphs. The original case (in blue) represents the base-case scenario

Table 11 Key results when varying annulus with original radii dimensions to 3.s.f

\begin{tabular}{lllll}
\hline Key results & Original & Case1 & Case2 & Case3 \\
\hline$T_{\mathrm{i}}\left({ }^{\circ} \mathrm{C}\right)$ & 11.1 & 10.9 & 11.2 & 11.8 \\
$T_{\mathrm{O}}\left({ }^{\circ} \mathrm{C}\right)$ & 50.0 & 48.5 & 51.8 & 49.6 \\
$\Delta T\left({ }^{\circ} \mathrm{C}\right)$ & 38.9 & 37.6 & 40.6 & 37.8 \\
$P_{\mathrm{i}}(\mathrm{MPa})$ & 4.97 & 5.90 & 4.87 & 1.35 \\
$P_{\mathrm{o}}(\mathrm{MPa})$ & 0.302 & 0.302 & 0.302 & 0.300 \\
$u_{\mathrm{F}}(\mathrm{m} / \mathrm{s})$ & 2.48 & 2.48 & 2.48 & 1.41 \\
$q_{\mathrm{Th}}(\mathrm{MW})$ & 1.46 & 1.43 & 1.50 & 1.45 \\
$\sigma_{\mathrm{A}}\left(\mathrm{m}^{2}\right)$ & 0.0137 & 0.00621 & 0.0291 & 0.0112 \\
$\sigma_{\mathrm{T}}\left(\mathrm{m}^{2}\right)$ & 0.00201 & 0.00201 & 0.00201 & 0.00354 \\
$\sigma_{\mathrm{A}} / \sigma_{\mathrm{T}}$ & 6.83 & 3.09 & 14.5 & 3.16 \\
\hline
\end{tabular}

Radii

Figure 9 shows the temperature and pressure distributions along the DBHE for varied radii. Two key scenarios were analysed: varying the inner annulus radius (Case1 and Case2) and increasing the tubing radii by a factor of 1.33 (Case3). Each scenario was then compared to the original base-case radii from Morita et al. (1992b), with a constant mass flow rate $\dot{m}=5 \mathrm{~kg} / \mathrm{s}$. Table 11 highlights the key thermodynamic properties from Fig. 9 and the output file for each scenario, respectively: $\Delta T$ between inlet $T_{\mathrm{i}}$ and outlet $T_{\mathrm{o}}$ points, the inlet $P_{\mathrm{i}}$ and outlet $P_{\mathrm{o}}$ pressure points, the simulated energy flow rate $q_{\mathrm{Th}}$, and the working fluid velocity $u_{\mathrm{F}}$ at the bottom of the well. The cross-sectional area values for the annulus $\left(\sigma_{\mathrm{A}}\right)$ and tubing $\left(\sigma_{\mathrm{T}}\right)$ are also quoted along with their ratio $\left(\sigma_{\mathrm{A}} / \sigma_{\mathrm{T}}\right)$.

Concerning the annulus comparison in Table 11, the bottomhole temperature decreases from 50.4 to $48.8^{\circ} \mathrm{C}$ alongside an inner radius reduction (Case1) and increases to $52.3{ }^{\circ} \mathrm{C}$ alongside an inner radius increase (Case2). This occurs due to variation in the annulus cross-sectional area $\left(0.0291 \mathrm{~m}^{2}\right.$ vs. $\left.0.00621 \mathrm{~m}^{2}\right)$. For Case2, the annulus 
cross-sectional area decreases the working fluid velocity down the annulus. This leads to a longer residence time and hence enhanced heat transfer within the wellbore, as discussed in Nalla et al. (2005). $T_{\mathrm{o}}$ also shows this trend, decreasing from 50.0 to $48.5^{\circ} \mathrm{C}$ for Case1 and increasing to $51.8^{\circ} \mathrm{C}$ for Case2.

$P_{\mathrm{i}}$ is seen to slightly increase from 4.97 to $5.90 \mathrm{MPa}$ for an inner annulus radius reduction (Case1) and decrease from 4.97 to $4.87 \mathrm{MPa}$ for an inner annulus radius increase (Case2) due to changes in the cross-sectional area ratio (3.09 vs. 14.5). Therefore, to impose a constant $\dot{m}$, the return pressure will decrease as a result of this increased crosssectional area ratio for Case2. Both Case1 and Case2 reach an equal bottomhole pressure of $33.1 \mathrm{MPa}$ which results in $P_{\mathrm{o}} \approx 0.302 \mathrm{MPa}$ for both cases. This occurs due to the constant cross-sectional area witnessed in the tubing $\left(0.00201 \mathrm{~m}^{2}\right)$.

$q_{\mathrm{Th}}$ increased from 1.46 to $1.50 \mathrm{MW}$ alongside an inner annulus radius increase (Case2) and slightly decreased to $1.43 \mathrm{MW}$ for an inner annulus radius reduction (Case1). The former is influenced by an increase in the working fluid velocity and crosssectional area as discussed previously. In addition, there is a decrease in frictional pressure down the annulus (254 Pa/m vs. $3.04 \mathrm{~Pa} / \mathrm{m}$ in Fig. 10), and hence an increased heat transfer and increased $\Delta T$ between the inlet and outlet points. Therefore, a radii increase in the annulus (Case2) is the best-case scenario here for maximal energy flow rate.

Case4 (tubing reduction by 1.22) failed to run for $\dot{m}=5 \mathrm{~kg} / \mathrm{s}$ due to a change in pressure into the wellbore that exceeded the limits of the software, 1000 bars (Renaud et al. 2018). For a constant $\dot{m}=5 \mathrm{~kg} / \mathrm{s}$, at time $t=0$, the pressure seen at the bottom of the well was $0.25 \times 10^{8} \mathrm{~Pa}$, but below the DBHE in the surrounding formation, the pressure reached $1 \times 10^{9} \mathrm{~Pa}$, i.e., 1000 bars. Therefore, a detailed comparison between Case 3 and Case 4 could not be achieved. Instead, an inner tubing radius increase (Case3) was compared with respect to the original radii-referring to Fig. 9 and Table 11.

A slight increase in temperature down the annulus from 50.4 to $50.9^{\circ} \mathrm{C}$ is seen for an inner tubing radius increase (Case3). This occurs due to a decreased upward velocity in the tubing $(1.41 \mathrm{~m} / \mathrm{s}$ vs. $2.48 \mathrm{~m} / \mathrm{s})$, leading to enhanced heat loss from the

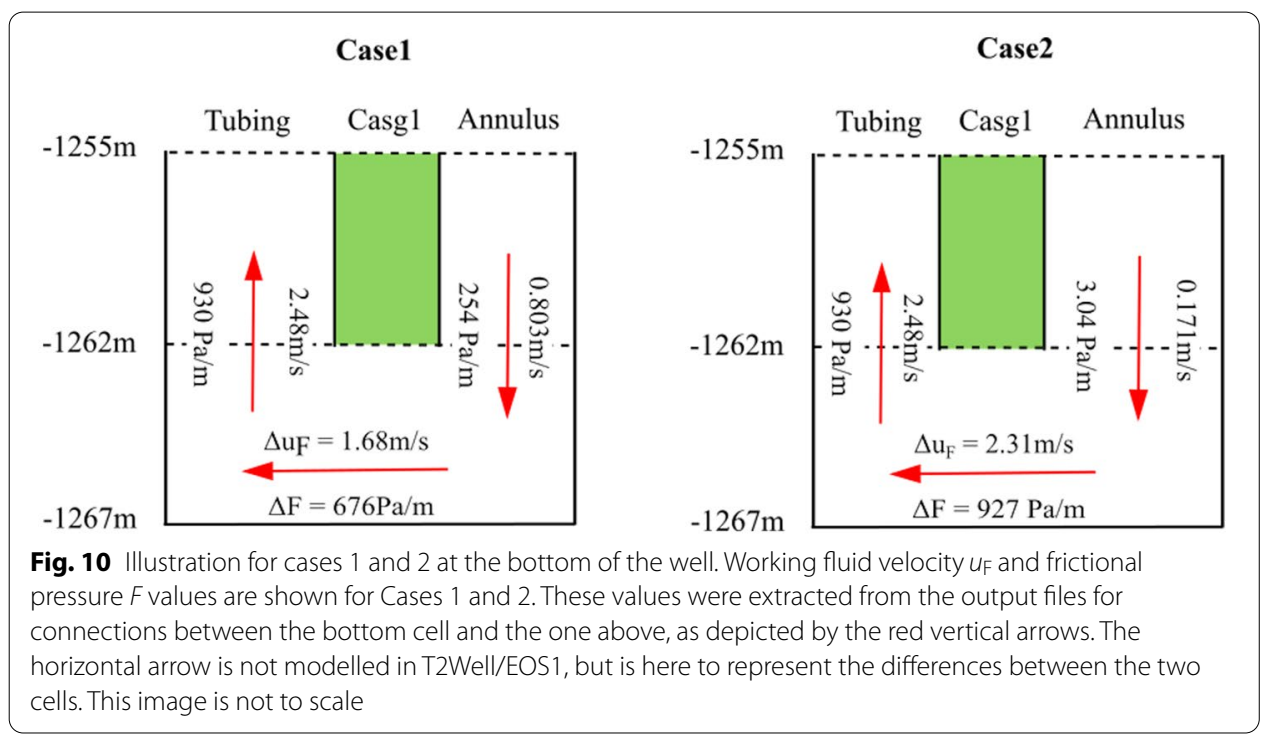


tubing into the annulus-see Fig. 11. In addition, the outlet temperature has slightly decreased $\left(49.6^{\circ} \mathrm{C}\right.$ vs. $\left.50.0^{\circ} \mathrm{C}\right)$ when the cross-sectional area in the tubing increased. Down the annulus however, the working fluid velocity has increased $(0.446 \mathrm{~m} / \mathrm{s}$ vs. $0.363 \mathrm{~m} / \mathrm{s})$, in addition to an increase in frictional pressure (50.6 Pa/m vs. $23.7 \mathrm{~Pa} / \mathrm{m})$.

To maintain the imposed mass flow rate $\dot{m}=5 \mathrm{~kg} / \mathrm{s}$ at the inlet point, the inlet pressure for Case3 has decreased ( $P_{\mathrm{i}}=1.35 \mathrm{MPa}$ vs. $4.97 \mathrm{MPa}$ ) following an increase in the working fluid velocity at the inlet point described above. In addition, the increased frictional pressure down the annulus $(50.6 \mathrm{~Pa} / \mathrm{m}$ vs. $23.7 \mathrm{~Pa} / \mathrm{m})$ consequently slows down the working fluid velocity in the tubing $(1.41 \mathrm{~m} / \mathrm{s}$ vs. $2.48 \mathrm{~m} / \mathrm{s})$ and a reduced inlet pressure is witnessed. Despite this ratio yielding a factor of 2 lower than that of the original radii ( 3.16 vs. 6.83 ), this loss in $P_{\mathrm{i}}$ is due to a slight reduction in the annulus cross-sectional area $\left(0.0112 \mathrm{~m}^{2}\right.$ vs. $\left.0.0137 \mathrm{~m}^{2}\right)$ and the reduced working fluid velocity witnessed in the tubing.

$q_{\mathrm{Th}}$ is seen to be nearly identical at $1.46 \mathrm{MW}$ for Case3 and the original radii. It can be inferred that when the inner tubing radius increases, there is little influence on the value of $q_{\mathrm{Th}}$ apart from a slight heat loss up the tubing. On the contrary, adjusting the tubing will affect the inlet pressure and hence the costs associated with the imposed energy flow rate. To avoid high energy consumption associated with a high injection pressure, a tubing reduction (Case3) could be considered a viable option for future designs to sustain a good energy flow rate.

In comparison, adjusting the annulus radii heavily influences the extent of heat transfer down the annulus. For an increased annulus radius, the heat transfer down the annulus increases and offers a higher $q_{\mathrm{Th}}$ from an increased bottomhole temperature. The best-case scenario concluded here is for a radius increase in the annulus (Case2) to increase the energy efficiency of the system. However, according to Nalla et al. (2005), adjusting the radii can incur high drilling costs-from the analysis, a tubing reduction (Case3) could be suggested as an alternative.

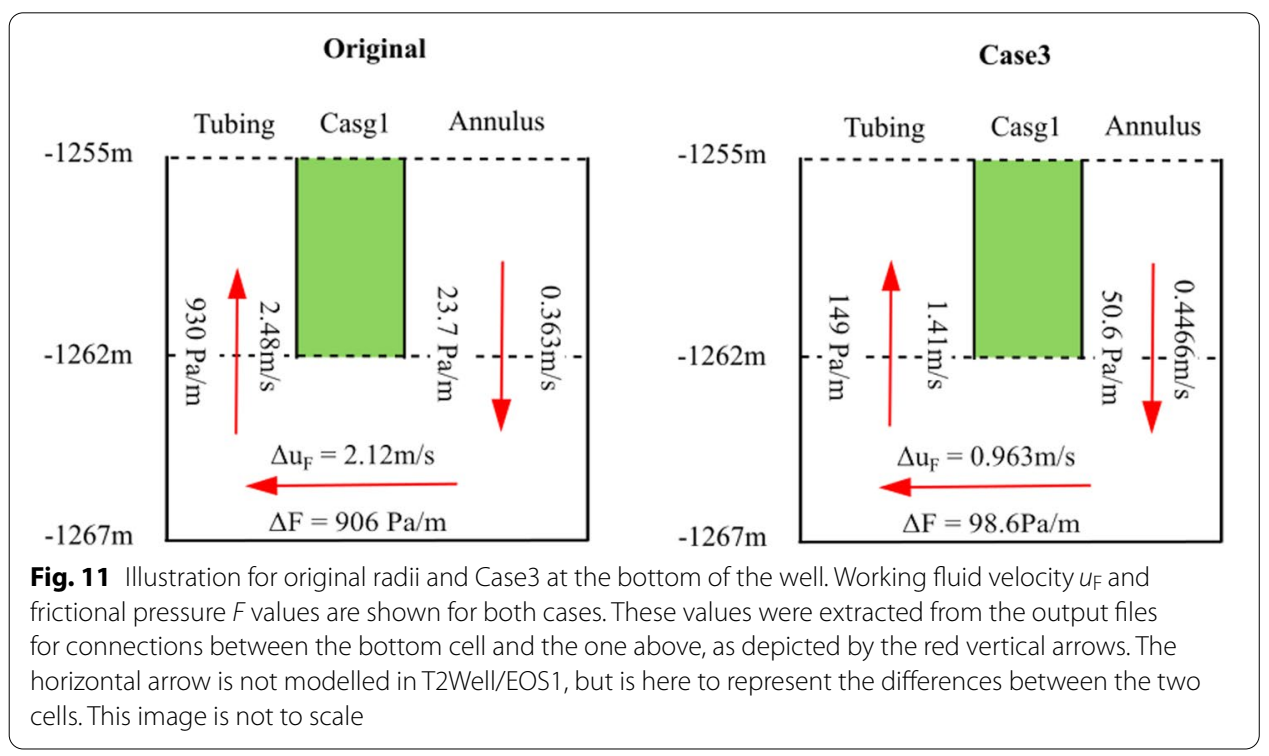


It is worth noting that the assumption of a constant wellbore radius along the wellbore is only a preliminary step, as wells are conventionally drilled with decreasing diameter sections at increasing depths (Nalla et al. 2005). However, keeping a constant radius for the entirety of the wellbore depth simplifies the model, as experimented in Morita et al. (1992b).

\section{Energy flow rate comparison between DBHE and NWG 55-29}

Assuming an average flow rate of $3.2 \mathrm{~kg} / \mathrm{s}$, and $\Delta T=94-12=82{ }^{\circ} \mathrm{C}$ obtained from the first NWG 55-29 flow back test (Cladouhos et al. 2016), in addition to $c_{\mathrm{P}}=4200 \mathrm{~J} / \mathrm{kg}^{\circ} \mathrm{C}$ for pure water, the energy flow rate obtained at the wellhead of NWG 55-29 is approximately $q_{\mathrm{Th}}=1.10 \mathrm{MW}$. Comparing this to the DBHE results at $3 \mathrm{~kg} / \mathrm{s}-q_{\mathrm{Th}}=1.14 \mathrm{MW}$ -it can be inferred that the DBHE offers a slightly higher energy flow rate at the wellhead compared to the NWG 55-29 open-loop well with a percentage increase of 3.44\%. It is important to note that this comparison is an estimate, and in reality, $\dot{m}$ and $c_{\mathrm{P}}$ will vary considerably with depth.

A comparison between the two designs is also interpreted by assessing the bottomhole temperature at a fixed depth of $3067 \mathrm{~m}$. Assuming no major temperature losses up the tubing $\left( \pm 5^{\circ} \mathrm{C}\right)$, the temperature at the wellbore bottom can be regarded as the temperature at the outlet point.

The highest bottomhole temperature observed in this sensitivity analysis without significant heat loss up the tubing is $73.4{ }^{\circ} \mathrm{C}$ for $3 \mathrm{~kg} / \mathrm{s}$ in the $\dot{m}$ parameter change, whereas the conventional open-loop NWG 55-29 wellbore reached a static bottomhole temperature of $331{ }^{\circ} \mathrm{C}$ (Cladouhos et al. 2016). Both examples are at a fixed depth of $3067 \mathrm{~m}$. Taking $\Delta q_{\mathrm{Th}}=0.956-(-0.200)=1.16 \mathrm{MW}$ as the simulated energy flow rate between the wellbore bottom and the inlet point for $3 \mathrm{~kg} / \mathrm{s}$, a comparison can be made with that obtained in the conventional NWG 55-29 well.

Assuming constant parameters $\dot{m}=3 \mathrm{~kg} / \mathrm{s}, c_{\mathrm{P}}=4200 \mathrm{~J} / \mathrm{kg}^{\circ} \mathrm{C}$ for pure water and $\Delta T=331-12=319^{\circ} \mathrm{C}$, then $q_{\mathrm{Th}}=4.02 \mathrm{MW}$ for the NWG 55-29 wellbore in comparison to $q_{\mathrm{Th}}=1.16 \mathrm{MW}$ for the DBHE design. This concludes that the closed-loop DBHE design offers an energy flow rate output approximately a factor of 3.5 lower than that of the conventional design.

However, the highest energy flow rate obtained in the $\dot{m}$ analysis was for $9 \mathrm{~kg} / \mathrm{s}-$ yielding $\Delta q_{\mathrm{Th}}=1.45-(-0.614)=2.06 \mathrm{MW}$ for a bottomhole temperature of $32.1{ }^{\circ} \mathrm{C}$ in comparison to $q_{\mathrm{Th}}=12.1 \mathrm{MW}$ for the NWG 55-29 wellbore at a fixed $\dot{m}=9 \mathrm{~kg} / \mathrm{s}$. This yields an energy flow rate drop for the DBHE of approximately a factor of 5.84 lower in comparison to the static NWG 55-29 bottomhole temperature of $331^{\circ} \mathrm{C}$.

These mass flow rates were chosen for comparison, because, according to Cladouhos et al. (2016), similar values were obtained for an initial flow test $(9.5 \mathrm{~kg} / \mathrm{s}$ down to 5.7 $\mathrm{kg} / \mathrm{s}$ after $1 \mathrm{~h}$, with an average flow rate $3.2 \mathrm{~kg} / \mathrm{s}$ ).

The estimate of $q_{\mathrm{Th}}$ for NWG 55-29 carries some uncertainty, especially when defining $c_{\mathrm{P}}$, because phase changes will occur with depth and the specific heat capacity will change. In the T2Well/EOS1 software, these phase changes are taken into account, so the simulated energy flow rate values will carry accuracy. Nevertheless, it can be inferred that the closed-loop design is associated with a lower heat extraction potential compared to that of an operating EGS (assuming the EGS is successful)-especially when 
the closed-loop design offers lower wellhead temperatures, according to Alimonti et al. (2018).

However, a DBHE solution for the current NWG 55-29 well would not require stimulation to create an artificial reservoir, and hence, less energy consumption is initially used up. This energy consumption for the current NWG 55-29 could outweigh the lower heat extraction potential seen from the DBHE design, hence bringing forward potential benefits for accommodating the DBHE design in this setting from this numerical study. Furthermore, the DBHE is a closed system, which enables easy monitoring and prevents fluid losses and pipe corrosion/blockage. For EGS projects where unexpected failures occur, the DBHE design could be an effective alternative. For example, an EGS site at Rosemanowes in Cornwall failed to create artificial fractures and suffered fluid loss of 70\%-leading to project abandonment in 1991 (Lu 2018). EGS activities in Cornwall, UK are ongoing and having the DBHE as a backup option could be beneficial, especially if drilling does not meet expectations.

While supercritical depths in the Newberry reservoir could not be modelled in this study due to software limitations, numerical wellbore-reservoir modelling will need to be further developed by adopting a supercritical equation of state (EOS1sc), see, for example, Croucher and O'Sullivan (2008), Battistelli et al. (2020), to assess the true thermal potential in these ultra-high temperature environments, notably targeted in the NDDP and IDDP projects.

It is also worth noting that only the thermal energy flow rate was quantified in this study. In fact, the overall net thermal capacity and total efficiency of the system should be investigated, considering the pumping power required for fluid circulation. Other future work entails:

- The return flow pressure at the bottom of the wellbore should be validated with another experimental study or Multiphysics software.

- Exploring a variety of working fluids, including water with salinity, carbon dioxide (Sun et al. 2019), or isobutane as a supercritical fluid (Wang et al. 2019).

- Investigating more complex unconventional DBHE designs, such as an artificial geyser concept (Heller et al. 2014).

- Investigating the effects of anisotropic reservoir permeability/porosity on DBHE thermal recovery.

- An economic analysis in the Newberry environment could also benefit the suitability of the DBHE design.

\section{Conclusion}

An in-depth sensitivity analysis was performed with reference to a base-case DBHE design from Morita et al. (1992b), and was modelled into the NWG 55-29 Newberry environment.

The best-case scenarios that offered maximal thermal efficiency was: $\dot{m}=5 \mathrm{~kg} / \mathrm{s}$, an insulated inner tubing for Casg1 of $\lambda=0.01038 \mathrm{~W} / \mathrm{mK}$, maintaining a high $\lambda$ for the outer casings (Casg2, Casg3) and the cement layers (Ceme1, Ceme2) and increasing the inner annulus radius (Case2), with a resulting thermal output $q_{\mathrm{Th}}=1.50 \mathrm{MW}$. 
Each parameter change offered some interesting insights. Altering the mass flow rate influenced the working fluid's velocity and its residence time down the annulus. An insulated inner tubing limits heat losses and minimises $\Delta T$ up the tubing. The outer casing properties do not significantly affect the heat transfer inside the wellbore, but should not be insulated to ensure sufficient heat transfer occurs between the reservoir and wellbore. The cement properties lead to a higher $q_{\text {Th }}$ when $\lambda$ was maximised and the use of graphite flakes in a conductive filler as opposed to conventional cement appears to be an efficient, though unproved concept, yielding a percentage increase in energy flow rate of $14.4 \%\left(q_{\mathrm{Th}}=1.67 \mathrm{MW}\right)$. Adjusting the radii dimensions will affect the residence time of the working fluid, similar to the sensitivity analysis conducted for varying the mass flow rate.

An energy flow rate comparison was made between this study and the conventional NWG 55-29 EGS well. The results showed that the DBHE was a factor of 3.5 and 5.84 lower when assuming constant mass flow rates of $3 \mathrm{~kg} / \mathrm{s}$ and $9 \mathrm{~kg} / \mathrm{s}$, respectively. While the DBHE design has a lower heat extraction and efficiency compared to the conventional EGS designs, the initial energy consumption to stimulate an artificial reservoir is not needed and could be an ideal candidate for future EGS projects where issues like induced seismicity, fluid losses, and contamination are mitigated. Future EGS projects should, therefore, consider the DBHE as an alternative design in situations where drilling may achieve original projects expectations.

Further work is needed to fully quantify the potential of the DBHE concept. The use of Multiphysics software and/or experimental data will be useful to validate the uncertainties in the pressure losses from the return fluid at the wellbore bottom. In addition, a variety of working fluid's and unconventional DBHE designs should be explored. Numerical wellbore-reservoir modelling tools will need to be further developed for supercritical environments, using the IDDP and NDDP projects for initial verification and calibration.

\section{List of symbols}

$\kappa$ : Index for the working fluid; $V$ : Volume $\left(\mathrm{m}^{3}\right) ; n$ : Outward normal vector; $\Gamma$ : Surface area of well side $\left(\mathrm{m}^{2}\right) ; M^{\kappa}$ : Mass accumulation term; $F^{k}$ : Key mass/energy transport terms; $q^{k}$ : Key source/sink terms; $\phi$ : Porosity; $S$ : Local saturation of phase; $\rho$ : Density of phase $\left(\mathrm{kg} / \mathrm{m}^{3}\right)$; X: Mass fraction of water in phase; $u$ : Velocity of fluid $(\mathrm{m} / \mathrm{s}) ; c$ : Specific heat capacity $\left(\mathrm{J} / \mathrm{kg}^{\circ} \mathrm{C}\right)$ ; T: Temperature $\left({ }^{\circ} \mathrm{C}\right) ; U$ : Specific thermal energy in the phase; $\lambda$ : Thermal conductivity $(\mathrm{W} / \mathrm{mK}) ; h$ : Specific enthalpy in phase ( $\mathrm{kJ} / \mathrm{kg}$ ); $k$ : Permeability ( $\mathrm{m}^{2}$ or Darcy); $\mu_{\mathrm{ph}}$ : Phase viscocity of the fluid (Pa s); P: Pressure (Pa); $g$ : Gravitational acceleration $\left(\mathrm{m} / \mathrm{s}^{2}\right)$; $z$ : Elevation in well $(\mathrm{m}) ; \theta$ : inclination angle of wellbore $\left({ }^{\circ}\right) ; \sigma$ : Cross-sectional area of wellbore $\left(\mathrm{m}^{2}\right) ; C_{0}$ : Profile parameter; $;$ : Volumetric flux of mixture $(\mathrm{m} / \mathrm{s}) ; K$ : Function to smooth transition of drift velocity from fluid stages; $K_{u}:$ Kutateladze number; $m(\theta)$ : Inclination of wellbore; $\gamma$ : Slip between two phases; $f$ : Apparent friction coefficient; $\dot{m}$ : Mass flow rate $(\mathrm{kg} / \mathrm{s}) ; r$ : Horizontal radii dimension $(\mathrm{m}) ; \Delta T$ : Change in temperature up tubing or down annulus $\left({ }^{\circ} \mathrm{C}\right) ; q_{\mathrm{Th}}$ : Energy flow rate (MW).

\section{Subscripts}

ph: Phase; L: Liquid phase; G: Gaseous phase; R: Rock properties; $a$ : Absolute permeability; $r$, ph: Relative permeability of a certain phase; d: Drift velocity; c: Characteristic velocity; m: Mixture; A: Annulus; T: Tubing; i: Inlet; o: Outlet; i, A: Inner annulus; o, T: Outer tubing; i, T: Inner tubing; F: Working fluid at wellbore bottom.

\section{Abbreviations}

DBHE: Deep borehole heat exchanger; EGS: Enhanced geothermal system; SEGS: Supercritical enhanced geothermal system; NDDP: Newberry Deep Drilling Project; IDDP: Icelandic Deep Drilling Project; HDR: Hot dry rock. 


\section{Authors' contributions}

TR assisted in numerical validation section and general advice on journal layout. LP and TR assisted in T2Well/EOS1 software manipulation. All authors read and approved the final manuscript.

\section{Funding}

This research is supported by the UK Engineering and Physical Sciences Research Council (EPSRC) [Grant number EP/ R513222/1].

\section{Availability of data and materials}

The datasets generated and/or analysed during the current study are available in the Enlighten repository https://doi. org/10.5525/gla.researchdata.1111.

\section{Competing interests}

The authors declare that they have no competing interests.

\section{Author details}

1 James Watt School of Engineering, University of Glasgow, Glasgow G12 8QQ, UK. ${ }^{2}$ Energy and Power, Cranfield University, Cranfield MK43 OAL, UK. ${ }^{3}$ Earth Sciences Division 90-1116, Lawrence Berkeley National Laboratory, Berkeley, CA 95720, USA.

Received: 7 June 2020 Accepted: 15 January 2021

Published online: 15 February 2021

\section{References}

Acuña J, Mogensen P, Palm B. Distributed thermal response tests on a multi-pipe coaxial borehole heat exchanger. HVAC\&R Res. 2011;17(6):1012-29. https://doi.org/10.1080/10789669.2011.625304.

Akbar S, Fathianpour N, Al Khoury R. A finite element model for high enthalpy two-phase flow in geothermal wellbores. Renew Energy. 2016;94:223-36. https://doi.org/10.1016/j.renene.2016.03.034.

Alimonti C, Soldo E. Study of geothermal power generation from a very deep oil well with a wellbore heat exchanger. Renew Energy. 2016;86:292-301. https://doi.org/10.1016/j.renene.2015.08.031.

Alimonti C, Berardi D, Bocchetti D, Soldo E. Coupling of energy conversion systems and wellbore heat exchanger in a depleted oil well. Geotherm Energy. 2016:4(1):11. https://doi.org/10.1186/s40517-016-0053-9.

Alimonti C, Soldo E, Bocchetti D, Berardi D. The wellbore heat exchangers: a technical review. Renew Energy. 2018;123:353-81. https://doi.org/10.1016/j.renene.2018.02.055.

Asadi I, Shafigh P, Abu Hassan ZFB, Mahyuddin NB. Thermal conductivity of concrete-a review. J Build Eng. 2018:20:81-93. https://doi.org/10.1016/j.jobe.2018.07.002.

Asl AH, Khajenoori M. Subcritical water extraction. In: Nakajima H, editor. Mass transfer, vol. 17. Rijeka: IntechOpen; 2013. https://doi.org/10.5772/54993.

Battistelli A, Finsterle S, Marcolini M, Pan L. Modeling of coupled wellbore-reservoir flow in steam-like supercritical geothermal systems. Geothermics. 2020;86:101793. https://doi.org/10.1016/j.geothermics.2019.101793.

Beier RA, Acuña J, Mogensen P, Palm B. Borehole resistance and vertical temperature profiles in coaxial borehole heat exchangers. Appl Energy. 2013;102:665-75. https://doi.org/10.1016/j.apenergy.2012.08.007.

Bertani R, Büsing H, Buske S, Dini A, Hjelstuen M, Luchini M, Manzella A, Nybo R, Rabbel W, Serniotti L, Science D, Team T. The first results of the descramble project. In: 43rd workshop on geothermal reservoir engineering, SGPTR: stanford geothermal program workshop report; 2018. p. 213.

Bonneville A, Cladouhos TT, Petty S, Schultz A, Sørlie C, Asanuma H, Frioleifsson GO, Jaupart C, de Natale G. The Newberry deep drilling project (NDDP) workshop. Sci Drill. 2018;24:79-86. https://doi.org/10.5194/sd-24-79-2018.

Breede K, Dzebisashvili K, Liu X, Falcone G. A systematic review of enhanced (or engineered) geothermal systems: past, present and future. Geotherm Energy. 2013. https://doi.org/10.1186/2195-9706-1-4.

Cladouhos TT. Newberry well 55-29 stimulation data: casing-cement-thermal-properties.xlsx. 2012. https://opene i.org/doe-opendata/dataset/newberry-well-55-29-stimulation-data.

Cladouhos TT, Petty S, Swyer MW, Uddenberg ME, Grasso K, Nordin Y. Results from Newberry volcano EGS demonstration, 2010-2014. Geothermics. 2016;63:44-61. https://doi.org/10.1016/j.geothermics.2015.08.009.

Cladouhos TT, Petty S, Bonneville A, Schultz A, Sorlie CF. Super hot EGS and the Newberry deep drilling project. In: 43rd workshop on geothermal reservoir engineering; 2018. p. 1-13.

Croucher AE, O'Sullivan MJ. Application of the computer code TOUGH2 to the simulation of supercritical conditions in geothermal systems. Geothermics. 2008;37(6):622-34. https://doi.org/10.1016/j.geothermics.2008.03.005.

DEEPEGS. IDDP-2 way forward workshop, saga report no. 11. Report, IDDP-Consortium and DEEPEGS. 2018.

DEEPEGS. IDDP-2 flow test kick-off meeting, saga report no. 12. Report, IDDP-Consortium and DEEPEGS. 2019

DiPippo R. Chapter 1: Geology of geothermal regions. Geothermal power plants principles, applications, case studies and environmental impact. New York: Elsevier Ltd.; 2015. p. 1-20. https://doi.org/10.1016/C2014-0-02885-7.

Dobson P, Asanuma H, Huenges E, Poletto F, Reinsch T, Sanjuan B. Supercritical geothermal systems-a review of past studies and ongoing research activities. In: 41st workshop on geothermal reservoir engineering; 2017. p. 1-13.

Falcone G, Liu X, Okech RR, Seyidov F, Teodoriu C. Assessment of deep geothermal energy exploitation methods: the need for novel single-well solutions. Energy. 2018;160:54-63. https://doi.org/10.1016/j.energy.2018.06.144.

Heller C, Teodoriu C, Falcone G. Harnessing deep geothermal heat using a new concept based on the geyser principle. In: Thirty-ninth workshop on geothermal reservoir engineering; 2014. p. 1-8.

Higgins B, Oldenburg C, Muir M, Pan L, Eastman A. Process modelling of a closed-loop $\mathrm{sCO}_{2}$ geothermal power cycle. In: 5th international supercritical $\mathrm{CO}_{2}$ power cycles symposium in Texas; 2016. p. 1-12. 
Holmberg H, Acuña J, Næss E, Sønju OK. Thermal evaluation of coaxial deep borehole heat exchangers. Renew Energy. 2016;97:65-766. https://doi.org/10.1016/j.renene.2016.05.048.

Hu X, Banks J, Wu L, Liu WV. Numerical modeling of a coaxial borehole heat exchanger to exploit geothermal energy from abandoned petroleum wells in hinton, alberta. Renew Energy. 2020;148:1110-23. https://doi.org/10.1016/j. renene.2019.09.141.

Ichim A, Teodoriu C, Falcone G. Influence of cement thermal properties on wellbore heat exchange. In: 41st workshop on geothermal reservoir engineering; 2016. p. 8.

IEA. Technology roadmap_-geothermal heat and power. France: Tech. rep; 2011.

IFC. The 1967 IFC formulation for industrial use: a formulation of the thermodynamic properties of ordinary water substance. Dusseldorf: IFC Secretariat; 1967.

Kim KH, Ree JH, Kim Y, Kim S, Kang SY, Seo W. Assessing whether the 2017 Mw 5.4 Pohang earthquake in South Korea was an induced event. Science. 2018;360(6392):1007-9. https://doi.org/10.1126/science.aat6081.

Kohl T, Salton M, Rybach L. Data analysis of the deep borehole heat exchanger plant Weissbad (Switzerland). Proc World Geotherm Congress. 2000;2000:3459-64.

Kohl T, Brenni R, Eugster W. System performance of a deep borehole heat exchanger. Geothermics. 2002;31:687-708.

Lu SM. A global review of enhanced geothermal system (EGS). Renew Sustain Energy Rev. 2018;81:2902-21. https:// doi.org/10.1016/j.rser.2017.06.097.

MIT. The future of geothermal energy, impact of enhanced geothermal systems (EGS) on the United States in the 21st century. Tech. Rep. INL/EXT-06-11746, MIT, Massachusetts. 2006.

Morita K, Matsubayashi O, Ki Kusunoki. Down-hole coaxial heat exchanger using insulated inner pipe for maximum heat extraction. Geotherm Resour Council Trans. 1985;9(1):45-50.

Morita K, Bollmeier WS, Mizogami H. Analysis of the results from the downhole coaxial heat exchanger (DCHE) experiment in Hawaii. 1992a. http://hdl.handle.net/10125/23600.

Morita K, Bollmeier WS, Mizogami H. An experiment to prove the concept of the downhole coaxial heat exchanger (DCHE) in Hawaii. 1992b. http://hdl.handle.net/10125/23601.

Muraoka H, Asanuma H, Tsuchiya N, Ito T, Mogi T, Ito H, The participants of the ICDP/JBBP Workshop. The Japan beyond-brittle project. Sci Drill. 2014;17:51-9. https://doi.org/10.5194/sd-17-51-2014.

Nalla G, Shook GM, Mines GL, Bloomfield KK. Parametric sensitivity study of operating and design variables in wellbore heat exchangers. Geothermics. 2005;34(3):330-46. https://doi.org/10.1016/j.geothermics.2005.02.001.

Nuclear-powernet. What is nusselt number. 2019. https://www.nuclear-power.net/nuclear-engineering/heat-trans fer/introduction-to-heat-transfer/characteristic-numbers/what-is-nusselt-number/.

Olasolo P, Juárez MC, Morales MP, D'Amico S, Liarte IA. Enhanced geothermal systems (EGS): a review. Renew Sustain Energy Rev. 2016;156:133-44. https://doi.org/10.1016/j.rser.2015.11.031

Pan L, Oldenburg CM. T2Well-an integrated wellbore-reservoir simulator. Comput Geosci. 2014;65:46-55. https://doi. org/10.1016/j.cageo.2013.06.005.

Pan L, Spycher N, Doughty C, Pruess K. ECO2N V2.0: a new TOUGH2 fluid property module for mixtures of water, $\mathrm{NaCl}$ and $\mathrm{CO}_{2}$. California: Earth Sciences Division, Lawrence Berkeley National Laboratory, University of California; 2005.

Pan L, Oldenburg C, Wu YS, Pruess K. T2Well/ECO2N version 1.0. California: Earth Sciences Division, Lawrence Berkeley National Laboratory, University of California; 2011

Pan L, Oldenburg CM, Freifeld BM, Jordan PD. Modeling the Aliso Canyon underground gas storage well blowout and kill operations using the coupled well-reservoir simulator T2Well. J Pet Sci Eng. 2018;161:158-74. https://doi. org/10.1016/j.petrol.2017.11.066.

Pruess K, Oldenburg C, Moridis G. TOUGH2 user's guide. California: Earth Sciences Division, Lawrence Berkeley National Laboratory, University of California; 2012.

Raymond J, Mercier S, Nguyen L. Designing coaxial ground heat exchangers with a thermally enhanced outer pipe. Geotherm Energy. 2015;3(1):7. https://doi.org/10.1186/s40517-015-0027-3

Reinsch T, Dobson P, Asanuma H, Huenges E, Poletto F, Sanjuan B. Utilizing supercritical geothermal systems: a review of past ventures and ongoing research activities. Geotherm Energy. 2017;5(1):1-25. https://doi.org/10.1186/ s40517-017-0075-y.

Renaud T, Stebel M, Verdin P, Falcone G. CFD modeling of a high enthalpy geothermal context. In: 43rd workshop of geothermal reservoir engineering, 2018. p. 1-8

Renaud T, Verdin P, Falcone G. Numerical simulation of a deep borehole heat exchanger in the Krafla geothermal system. Int J Heat Mass Transf. 2019;143:118496. https://doi.org/10.1016/j.ijheatmasstransfer.2019.118496.

Renaud T, Verdin P, Falcone G, Pan L. Heat Transfer Modelling of an Unconventional, Closed-Loop Geothermal Well. In: World Geothermal Congress 2020 Reykjavik [Internet]. Reykjavik; 2021 [cited 2021 Jan 15]. Available from: https //pangea.stanford.edu/ERE/db/WGC/Abstract.php?PaperID=5695.

Sammel EA, Ingebritsen SE, Mariner RH. The hydrothermal system at Newberry volcano, Oregon. J Geophys Res Solid Earth. 1988;93(B9):10149-62. https://doi.org/10.1029/JB093iB09p10149.

Seyidov F. Investigation of the feasibility and efficiency of deep borehole heat exchangers. Master's thesis, TU Clausthal, Clausthal University of Technology. 2016.

Song X, Zheng R, Li G, Shi Y, Wang G, Li J. Heat extraction performance of a downhole coaxial heat exchanger geothermal system by considering fluid flow in the reservoir. Geothermics. 2018;76:190-200. https://doi. org/10.1016/j.geothermics.2018.07.012.

Sonnenthal E, Spycher N, Callahan O, Cladouhos TT, Petty S. A thermal-hydrological-chemical model for the enhanced geothermal system demonstration project at Newberry. 2012.

Sudarmadi E, Zarrouk SJ, Croucher AE, Bramantyo EA. Modelling production from supercritical geothermal reservoirs. In: New Zealand geothermal workshop 2012 Proceedings. 2012;40:1-6.

Sui D, Wiktorski E, Røksland M, Basmoen TA. Review and investigations on geothermal energy extraction from abandoned petroleum wells. J Pet Explor Prod Technol. 2019;9(2):1135-47. https://doi.org/10.1007/s1320 2-018-0535-3. 
Sun X, Wang Z, Liao Y, Sun B, Gao Y. Geothermal energy production utilizing a U-shaped well in combination with supercritical CO2 circulation. Appl Therm Eng. 2019;151:523-35. https://doi.org/10.1016/j.appltherma leng.2019.02.048.

Tang H, Xu B, Hasan AR, Sun Z, Killough J. Modeling wellbore heat exchangers: fully numerical to fully analytical solutions. Renew Energy. 2019;133:1124-35. https://doi.org/10.1016/j.renene.2018.10.094.

Toth A. Chapter 13: Borehole heat exchangers. In: Flow and heat transfer in geothermal systems. Amsterdam: Elsevier Inc: 2015. p. 287-298. https://doi.org/10.1016/C2013-0-13065-6.

Wang Y, Zhang L, Cui G, Kang J, Ren S. Geothermal development and power generation by circulating water and isobutane via a closed-loop horizontal well from hot dry rocks. Renew Energy. 2019;136:909-22. https://doi.org/10.1016/j. renene.2019.01.042.

\section{Publisher's Note}

Springer Nature remains neutral with regard to jurisdictional claims in published maps and institutional affiliations.

Submit your manuscript to a SpringerOpen ${ }^{\circ}$ journal and benefit from:

- Convenient online submission

- Rigorous peer review

Open access: articles freely available online

- High visibility within the field

- Retaining the copyright to your article

Submit your next manuscript at $\gg$ springeropen.com 